TRANSIENT TESTS OF THE BSR-II CORE IN THE SPERT I FACILITY

MASTER

\title{
L. A. Stephan
}

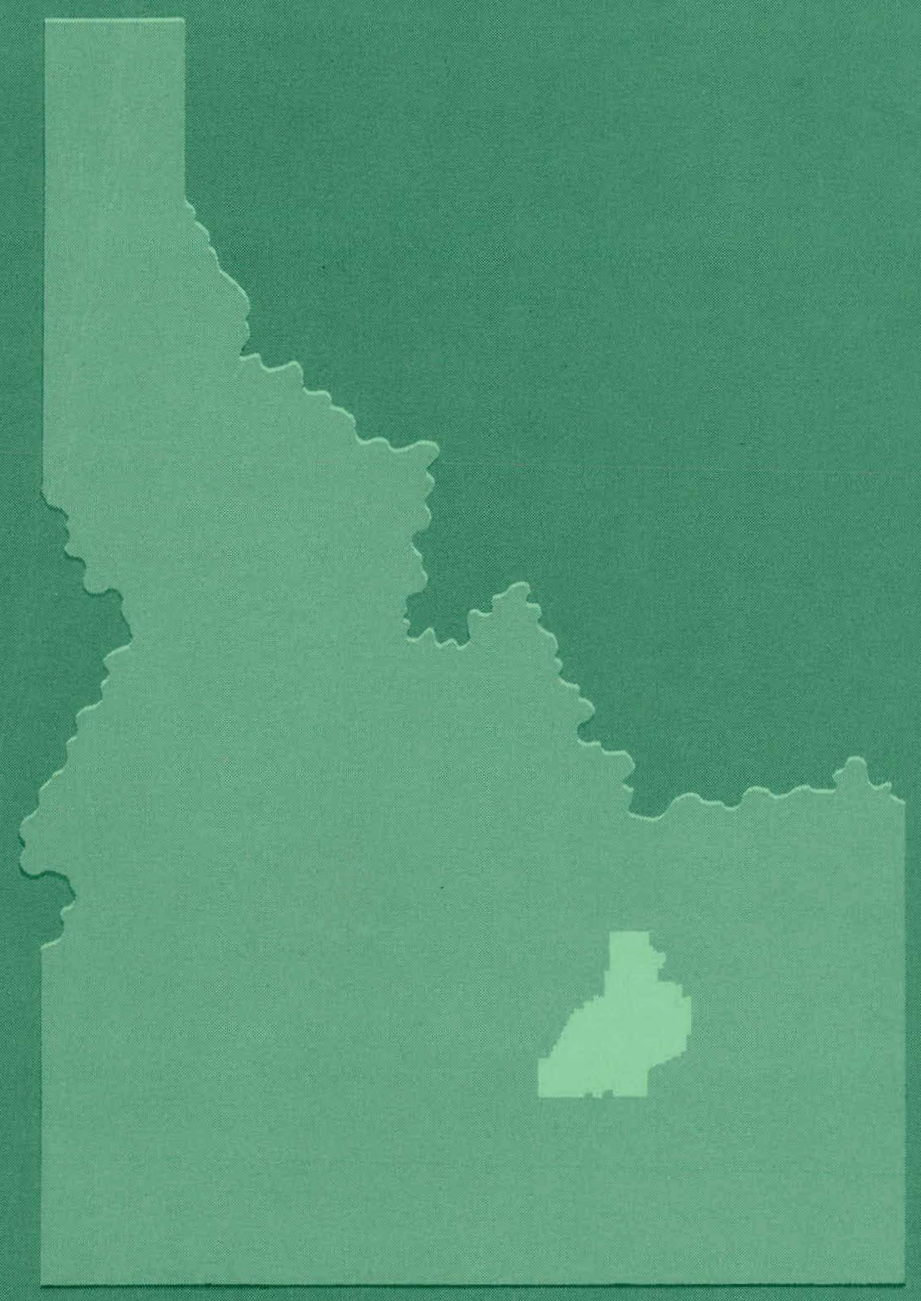

\section{PHILLIPS PFTROLIUM cOMPANY}

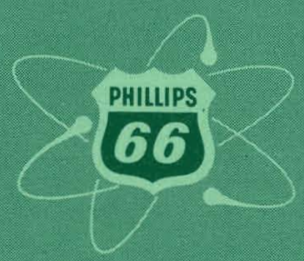

ATOMIC ENERGY DIVISION

NATIONAL REACTOR TESTING STATION US ATOMIC ENERCY COMMISSION 


\section{DISCLAIMER}

This report was prepared as an account of work sponsored by an agency of the United States Government. Neither the United States Government nor any agency Thereof, nor any of their employees, makes any warranty, express or implied, or assumes any legal liability or responsibility for the accuracy, completeness, or usefulness of any information, apparatus, product, or process disclosed, or represents that its use would not infringe privately owned rights. Reference herein to any specific commercial product, process, or service by trade name, trademark, manufacturer, or otherwise does not necessarily constitute or imply its endorsement, recommendation, or favoring by the United States Government or any agency thereof. The views and opinions of authors expressed herein do not necessarily state or reflect those of the United States Government or any agency thereof. 


\section{DISCLAIMER}

Portions of this document may be illegible in electronic image products. Images are produced from the best available original document. 


\section{PRICE $\$ 1.00$ \\ Available from the \\ Office of Technical Services \\ U.S. Department of Commerce \\ Washington 25, D. C.}

\section{LEGAL NOTICE}

This report was prepared as an account of Government sponsored work. Neither the United States, nor the Commission, nor any person acting on behalf of the Commission:

A. Makes any warranty or representation, express or implied, with respect to the accuracy, completeness, or usefulness of the information contained in this report, or that the use of any information, apparatus, method, or process disclosed in this report may not infringe privately owned rights; or

B. Assumes any liabilities with respect to the use of, or for damages resulting from the use of any information, apparatus, method, or process disclosed in this report.

As used in the above, "person acting on behalf of the Commission" includes any employee or contractor of the Commission, or cmployee of such contractor, to the extent that such employee or contractor of the Commission, or employee of such contractor prepares, disseminates, or provides access to, any information pursuant to his employment or contract with the Commission, or his employment with such contractor. 


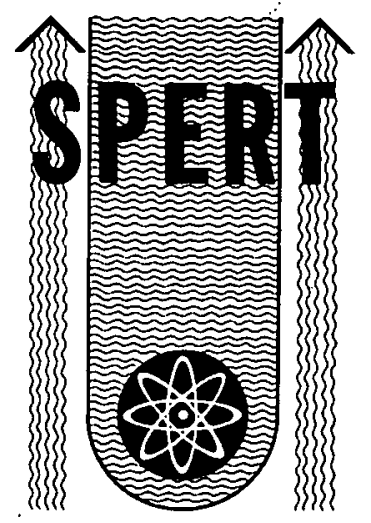

IDO-16768

AEC Research and Development Report

Reactor Technology

TID-4500 (19th Ed.)

Issued: April 5, 1963

TRANSIENT TESTS OF THE BSR-II CORE

IN THE SPERT I FACILITY

by

L. A. Stephan

PHILLIPS

PETROLEUM

COMPANY

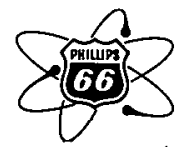

Atomic Energy Division

Contract AT $(10.1) \cdot 205$

Idaho Operations Office

U. S. ATOMIC ENERGY COMMISSION 


\section{ACKNOWLEDGEMENT}

The author wishes to express his appreciation to the following persons and groups of persons for their assistance during the performance of the BSR-II program at Spert and/or the preparation of this report:

Mr. F. L. Bentzen for his overall guidance of the Spert BSR-II program and for his many contributions and suggestions made during the writing of this report.

Mr. J. G. Crocker for his general assistance in the preparation and editing of the report. irafts.

The following personnel whose contributions to the Spert quarterly technical reports for the fourth quarter of 1959 and the first half of 1960 [2, 3, 4] formed the basis for a large portion of this report: Mr. A. H. Spano, Mr. T. M. Quigley, Mr. J. Siegwarth, Mr. H. L. Whitener, Mr. V. C. Kobold, and Mr. K. E. Krauter.

The following personnel from the ORNL Neutron Physics and Reactor Controls Department for direct assistance and counsel during the performance of the Spert BSR-II program: Dr. E. G. Silver, Mr. R. T. Santoro, Mr. J. R. Tallackson, Mr. R. Wittenburg, and Mr. K. M. Henry. 


\begin{abstract}
A series of transient tests was performed in Spert I with the Bulk Shielding Reactor II (BSR-II) core to determine the self-limiting properties of this core and to test the response of the reactor control system. The experimental program included measurements of the static parameters, self-limiting transient tests, control-system-shutdown transient tests, low-level start-up tests, and determinations of the reduced prompt neutron lifetime by dynamic and static techniques. The kinetic behavior of the BSR-II self-limiting transient tests showed a general similarity to behavior of self-limiting transient tests performed on other plate-type cores tested at Spert. The control system was found to be more effective in terminating power bursts than was the inherent self-shutdown of the reactor for excursions initiated by reactivity additions of up to an excess reactivity of about 1.8 dollars, corresponding to a reactor period of about $3 \mathrm{msec}$. For reactivity insertions larger than 1.8 dollars, self-shutdown was more effective than shutdown by external controls in limiting the excursion. In the short-period region where limited or total core damage can occur, no increased protection to the reactor is provided by the control system.
\end{abstract}




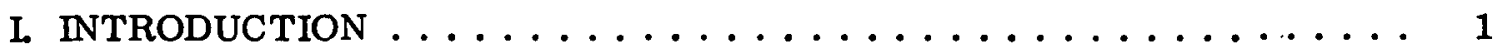

II. STATIC MEASUREMENTS $\ldots \ldots \ldots \ldots \ldots \ldots \ldots \ldots \ldots \ldots \ldots$

A. Introduction ......................... 2

B. Description of the BSR-II Reactor as Installed in the Spert I Faoility . . . . . . . . . . . . . . . . . . 3

C. Static Measurements for the BSR-II Core in Spert I . . . . . . . 5

III. TRANSIENT TESTS . . . . . . . . . . . . . . . . . . . . 12

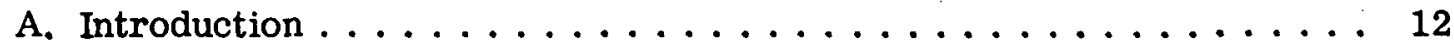

B. Self-Limiting Transient Tests . . . . . . . . . . . . . 12

C. Safety System Tests . . . . . . . . . . . . . . . . . 14

D. Low-Level Start-Up Tests . . . . . . . . . . . . . . . 19

IV. DETERMINATION OF THE REDUCED PROMPT NEUTRON LIFETIME . . . . . . . . . . . . . . . 23

A. Introduction . . . . . . . . . . . . . . . . . . . 23

B. Step-Transient Measurements .................. 23

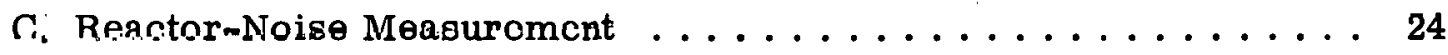

D. Static $1 / \mathrm{v}$-Absorber Measurement . . . . . . . . . . . . . 26

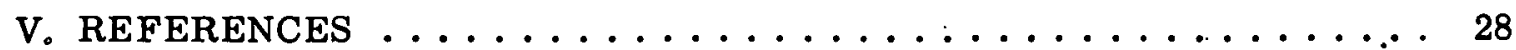

APPENDIX A - POWER AND TEMPERATURE DATA FROM SELF-LIMITING POWER EXCURSIONS . . . . . . . . 29

APPENDIX B - COMPARISON OF MECHANICAL AND SELF-SHUTDOWN POWER DATA . . . . . . . . . . 34

FIGURES

1. Photograph of BSR-II core installation in Spert I .......... 2

2. Vertical section, BSR-II core installation in Spert I . . . . . . . . 3 
3. Detalls of the BSR-II control rod, transient rod, and fuel assemblies . . 4

4. BSR-II safety system for the Spert installation . . . . . . . . . . 6

5. BSR-II core configuration (6070-g loading) in Spert I . . . . . . . 6

6. Integral worth of single control rod in 6070-g BSR-II core . . . . . . . 7

7. Integral worth of a single control rod in 6140-g BSR-II core . . . . . 7

8. Integral worth of two control rods in 6070-g BSR-II core . . . . . . . 7

9. Integral worth of three control rods in 6070-g BSR-II core . . . . . . 7

10. BSR-II core configuration showing location of folls for flux measurements .................... 8

11. Vertical flux distribution in center of assembly position $32 \ldots \ldots$

12. Horizontal flux distributions through assembly positions 31,21 , and $11 \ldots \ldots \ldots \ldots \ldots$

13. Horizontal flux distributions through assembly positions 33,23 , and $13 \ldots \ldots \ldots \ldots . \ldots \ldots$

14. Horizontal flux distributions through assembly positions 33,32 , and 31 and adjacent reflector regions............. 9

15. Temperature defect vs temperature for BSR-II core in Spert I . . . . 10

16. Reactivity loss vs void volume for BSR-II core in Spert I . . . . . . 10

17. Peak power vs reciprocal period for BSR-II and $\mathrm{P}\left(" \mathrm{APPR} \mathrm{R}^{n}\right.$ ) cores (self-shutdown tests) ............... 13

18. Maximum plate temperature vs reciprocal period for BSR-II and P("APPR") cores (self-shutdown tests) . . . . . . . . . 14

19. Fuel plate surface temperature at the time of peak power vs reciprocal period (self-shutdown tests). .............. 15

20. Energy release to the time of peak power vs reciprocal period (self-shutdown tests). . . . . . . . . . . 15

21. Peak power vis reciprocal period for various modes of shutdown ... 16

22. Insertion rate of reactivity for various groups of cunlrol rods . . . . 17

23. Elapsed time from rod release to the time of peak power vs reciprocal period .................. 18

24. Compensated reactivity and inserted reactivity vs reciprocal period . $\quad 20$ 
25. Estimated waiting time for attainment of stable reactor period vs reciprocal period ................. 21

26. Prompt reactivity vs reciprocal period for BSR-II . . . . . . . . . . . 24

27. Block diagram of reactor noise instrumentation $\ldots \ldots \ldots \ldots \ldots$

A-1. Self-limiting test, $\tau_{0}=1.12 \mathrm{sec} \ldots \ldots \ldots \ldots \ldots \ldots \ldots \ldots \ldots \ldots \ldots . \ldots \ldots$

A-2. Self-limiting test, $\tau_{0}=540 \mathrm{msec} \ldots \ldots \ldots \ldots \ldots \ldots$

A-3. Self-limiting test, $\tau_{o}=190 \mathrm{msec} \ldots \ldots \ldots \ldots \ldots \ldots$

A-4. Self-limiting test, $\tau_{0}=87 \mathrm{msec} \ldots \ldots \ldots \ldots \ldots \ldots \ldots$

A-5. Self=limiting test, $\tau_{0}=55 \mathrm{msec} \ldots \ldots \ldots \ldots \ldots \ldots \ldots \ldots \ldots$

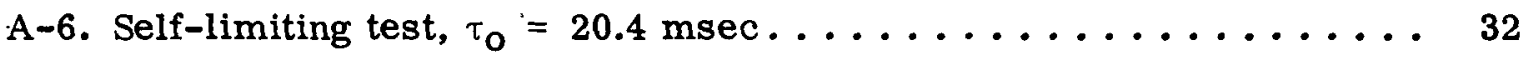

A-7. Self-11miting test, $\tau_{0}=19.6$ msec. . . . . . . . . . . . 32

A-8. Self-limiting test, $\tau_{0}=15 \mathrm{msec} \ldots \ldots \ldots \ldots \ldots$

B-1. Three-rod level scram, $\tau_{0}=75 \mathrm{msec} \ldots \ldots \ldots \ldots \ldots \ldots$

B-2. Three-rod level scram, $\tau_{0}=11 \mathrm{msec} \ldots \ldots \ldots \ldots \ldots \ldots$

B-3. Three-rod level scram, $\tau_{o}=6.5 \mathrm{msec} \ldots \ldots \ldots \ldots \ldots$

B-4. Three-rod level scram, $\tau_{0}=4.7 \mathrm{msec} \ldots \ldots \ldots \ldots$

B-5. Two-rod level scram, $\tau_{0}=6.8 \mathrm{msec} \ldots \ldots \ldots \ldots \ldots$

B-6. Foir -rnd level scram, $\tau_{0}-5.0 \mathrm{mscc} \ldots \ldots \ldots \ldots \ldots \ldots \ldots$

B-7. Three-rud periud suram, $\tau_{0}=6.2 \mathrm{msec} \ldots \ldots \ldots \ldots \ldots$

B-8. Three-rod period scram, $\tau_{0}=3.0 \mathrm{msec} \ldots \ldots \ldots \ldots$

TABLE

I. Determination ol $\ell / B_{\text {eff }}$ for the BSR-II Reactor $\ldots \ldots \ldots \ldots \ldots$ 


\section{INTRODUCTION}

The Spert project is operated by Phillips Petroleum Co. at the National Reactor Testing Station (NRTS) as a part of the Atomic Energy Commission's reactor safety program. An important part of the Spert experimental program is the study of the kinetic behavior of various reactor types under extreme accident conditions. As a part of this study, an experimental program was conducted in the Spert I reactor facility with the Bulk Shielding Reactor II (BSR-II) core to investigate the kinetic behavior of such a core and to evaluate the performance of fast mechanical safety systems in limiting reactor power excursions. The experimental program was started in October 1959 and was completed in April 1960.

The BSR-II ${ }^{[1]}$ is a compact, light-water-moderated research reactor consisting of stainless-steel-clad, plate-type fuel elements using a cermet of highly enriched $\mathrm{UO}_{2}$ and stainless steel as fuel. It was designed at Oak Ridge National Laboratory (ORNL) for pool-type use to be employed alternately with the BSR-I core at the ORNL Bulk Shielding Facility (BSF) for experiments related to shielding development. A fast-control (safety) system, designed by ORNL personnel for use with the BSR-II reactor, was characterized by fast electronic scram circuits, short-release-time holding magnets, low-inertia control rods and coiled springs for initial acceleration of the control rods. The transient experiments performed at Spert provided an experimental evaluation of the effectiveness of such a safety system in limiting reactor power excursions.

The testing program, as conducted at Spert, was a joint effort of Spert personnel and of ORNL Neutron Physics and Reactor Controls Department personnel. The program included measurements of the static characteristics of the core (flux distribution, void coefficient, etc) and power excursions which were limited by the inherent self-limiting properties of the core and/or by the BSR-II safety program. This report is a summary of the various tests that were conducted at Spert with the BSR-II core and includes data previously published in other Spert publications $[2,3,4,5]$. 


\section{STATIC MEASUREMENTS}

\section{A. Introduction}

Criticality tests and preliminary measurements of the static reactor parameters were made at ORNL before transporting the reactor to the NRTS. After the core and the control system had been installed in the Spert I facility the nominal BSR-II core loading was modified to obtain an excess reactivity sufficient to meet the requirements of the Spert kinetic testing program. Reactor statics measurements made at Spert included neutron flux distributions, control rod worths, and void and temperature coefficients. Descriptions of the Spert BSR-II installation and the static experiments are included in the following sections.

B. Description of the BSR-II Reactor as Installed in the Spert I Facility

The BSR-II reactor as installed in the Spert I reactor tank is shown in Figure 1. Figure 2 is a vertical section drawing of the installation.

The BSR-II core consists of 25 fuel elements in a $5 \times 5$ array,forming an active region approximately 15 in. square $x 15$ in. high. When installed in the BSF the core consists of 21 standard fuel assemblies plus 4 assemblies modified for the passage of control rods. The Spert installation was essentially

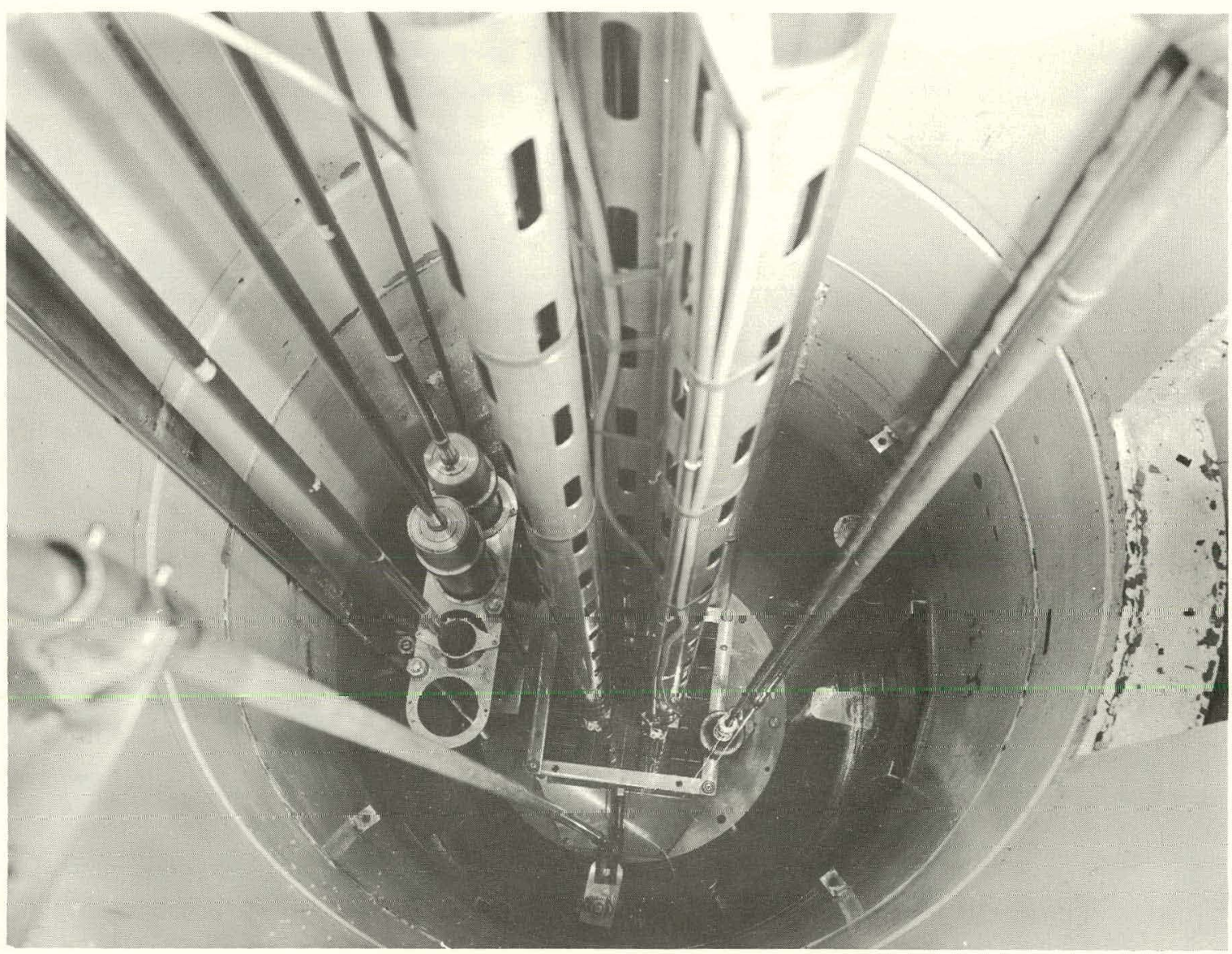

Fig. 1 Photograph of BSR-II core installation in Spert I. 

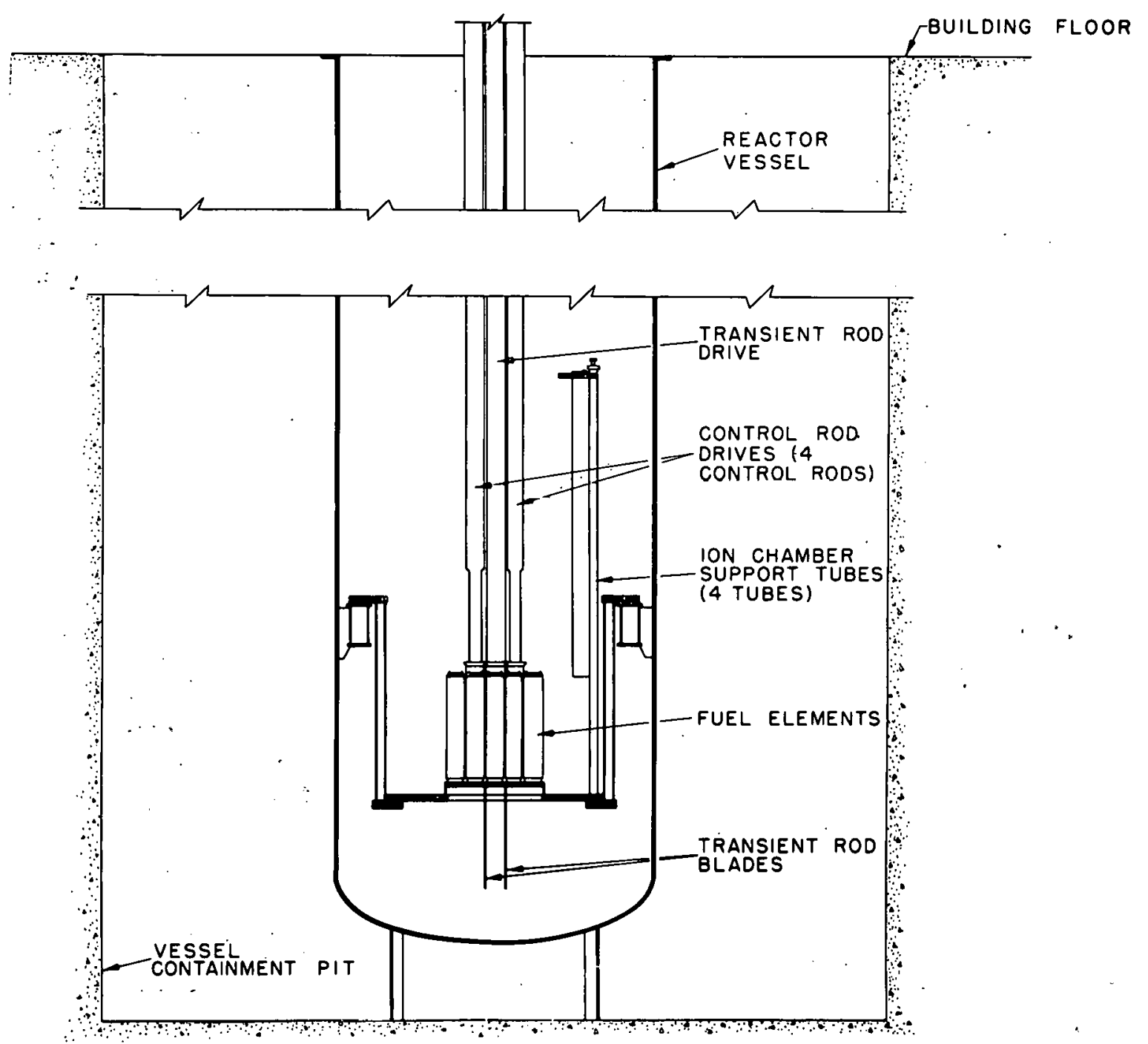

Fig. 2 Vertical section, BSR-II core installation in Spert I.

the same as that used in the BSF, except that the central fuel element and two adjacent elements were modified for passage of special fuel-poison blades. These blades comprise the transient rod, used for initialing reactor power excursions by the rapid addition of reactivity to the system.

The flat-plate-type fuel assemblies are shown schematically in Figure 3. The fuel material is a cermet consisting of type 347 stainless steel and $\mathrm{UO}_{2}$, the uranium enriched to $93 \mathrm{wt} \%$ in U-235. The cladding and side plates are type 347 stainless steel. The standard fully loaded fuel element contains a nominal $290 \mathrm{~g}$ of $\mathrm{U}-235$ with approximately $25 \mathrm{wt} \% \mathrm{UO}_{2}$ in the cermet. Fuel elements with one-half and with one-quarter of the nominal fuel loading also are available, making it possible to load 25 assembly cores with various amounts of excess reactivity.

The control rod fuel elements, also shown in Figure 3, are identical to the standard fuel elements, except that the width of the fuel plates is reduced to provide space at each side for passage of the poison control plates. The nominal U-235 content of the control rod fuel assembly is $224 \mathrm{~g}$. 


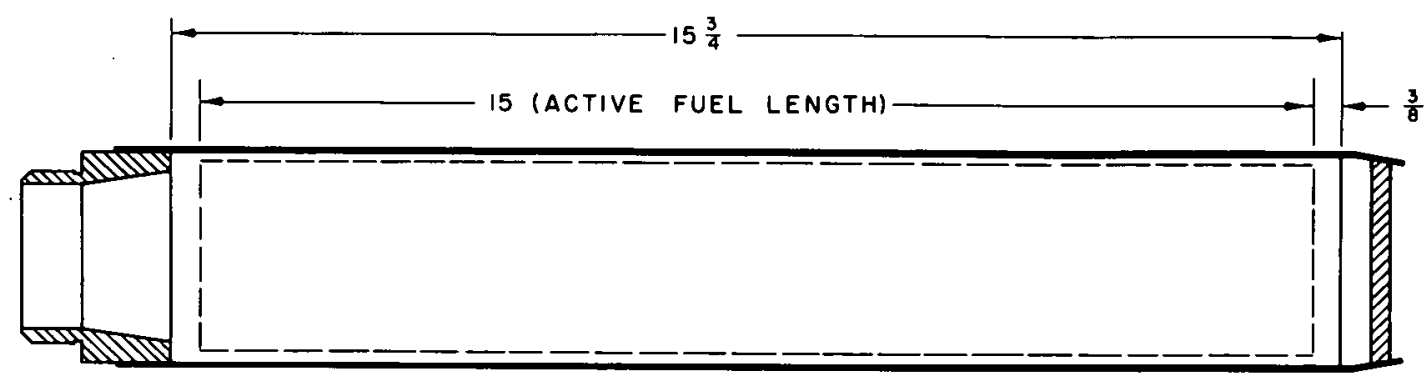

TYPICAL FUEL ASSEMBLY

VERTICAL CROSS-SECTION
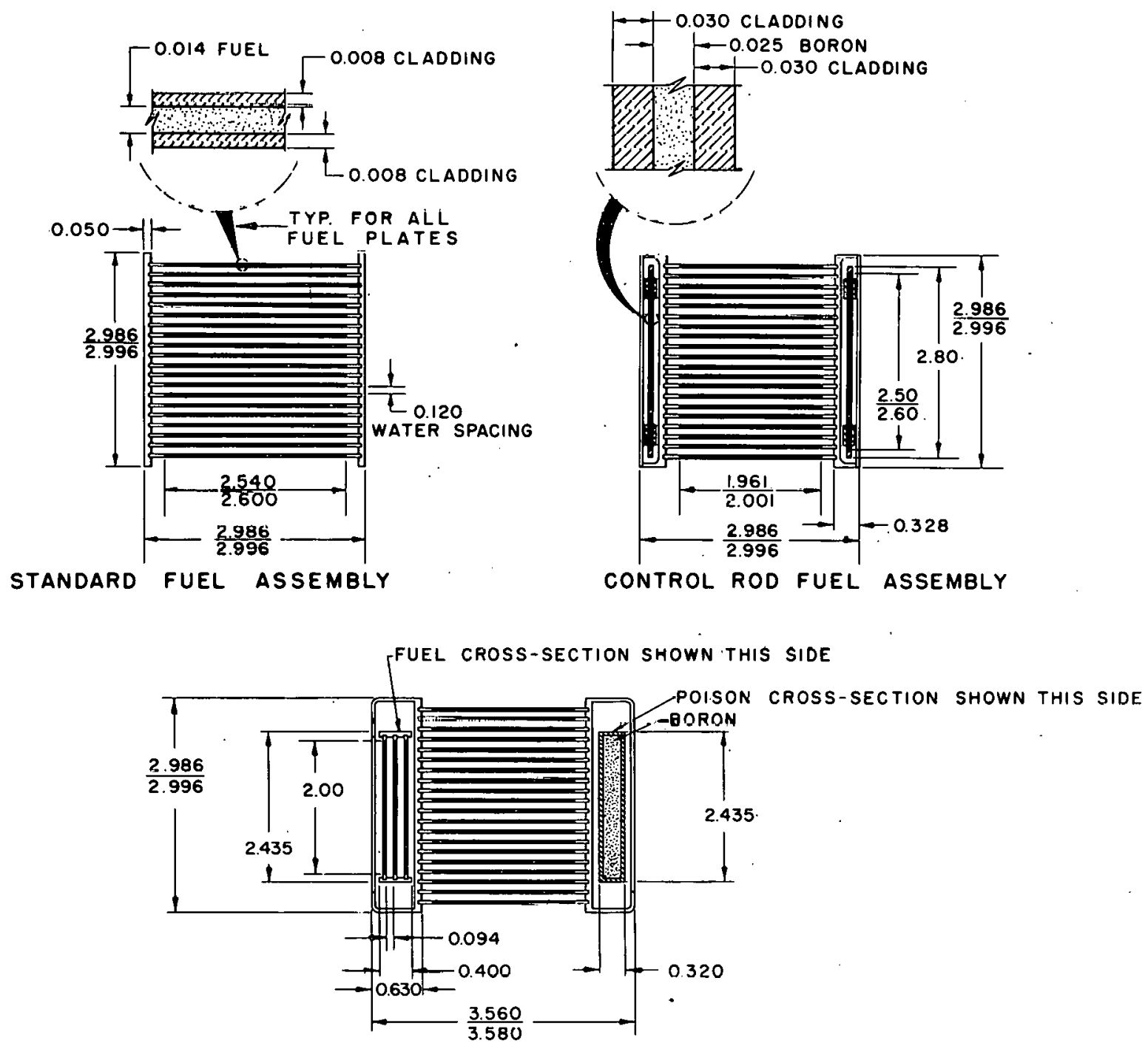

TRANSIENT ROD FUEL ASSEMBLY

Fig. 3 Details of the BSR-II control rod, transient rod, and fuel assemblies. 
The poison sections of the control plates consist of a dispersion in iron of $6 \mathrm{~g}$ of boron enriched to $85 \%$ in B-10. The plates are clad with type 347 stainless steel.

A cross section of the transient rod fuel assembly also is shown in Figure 3. The fuel portion has the samedimensions and loading as the control rod elements. Because of the wide slots for passage of the transient rod blades, the transient rod assembly extends beyond the confines of the normal 3.040-in.-square fuel cell on two sides. The extensions are accommodated by removal of two fuel plates from each of the adjacent standard assemblies. Each of these two modified assemblies has 18 fuel plates, with a nominal U-235 loading of $261 \mathrm{~g}$. The transient rod consists of two fuel-poison blades. The upper part of the blade is a fuel-bearing section and the lower part is a poison section, so that fuel is added to the core as poison is ejected. The fuel section of each blade consists of three fuel plates of the same dimension as the fuel plates in the control rod fuel assemblies. The U-235 content for the two blades is approximately $67 \mathrm{~g}$. The poison section consists of a type 347 stainless steel box filled with compacted boron enriched to $90 \%$ in B-10.

The pair of blades, for each control rod element, is joined at the top to the drive unit through a yoke, so that each pair of blades moves as a unit.

The control- and transient-rod drive mechanisms for the Spert installation are identical to those used in the BSF. The rods are held to the drives by magnets and spring loading is employed for rapid acceleration upon magnet release. The entire mechanism consists of a drive motor, magnet armature, accelerating spring, and a dashpot-and-piston shock absorber. The assembly is enclosed in a 3-in.-diameter tube, the lower end of which is attached to the top of the fuel element.

The circuit for the BSR-II control system tested in the Spert experimental program, described in block diagram form in Figure 4, is similar to that used in many reactors. A typical malfunction warning system, used throughout the safety system, senses failures of power supplies, disconnected cables, faulty tube filaments, and various tube and resistor failures.

\section{Static Measurements for the BSR-II Core in Spert I}

1. Critical-Loading and Control Rod Calibrations. The first critical loading for a BSR-II core in the Spert I reactor consisted of 21 fuel assemblies (a $5 \times 5$ array without corners) containing a total of $5780 \mathrm{~g}$ of U-235. Criticality was achieved with the four control rods withdrawn 12.15 in. from the bottom of the core, and the fuel section of the transient rod in the core.

For the experimental transient program an available excess reactivity of approximately two dollars was required. This was obtained by adding partially loaded fuel assemblies to the corner positions of the 21-assembly core. These assemblies have the same dimensions and number of plates as the standard assemblies but have a lighter loading of uranium. In order to evaluate the effectiveness of the safety control system under various operating conditions it was necessary to obtain the reactivity worth of the control rods in various configurations. Such measurements were made for two core loadings. The first core, shown in Figure 5, included four one-quarter-loaded corner assemblies and contained a total U-235 mass of $6070 \mathrm{~g}$. The second core had three onequarter-loaded corner assemblies and one one-half-loaded corner assembly 


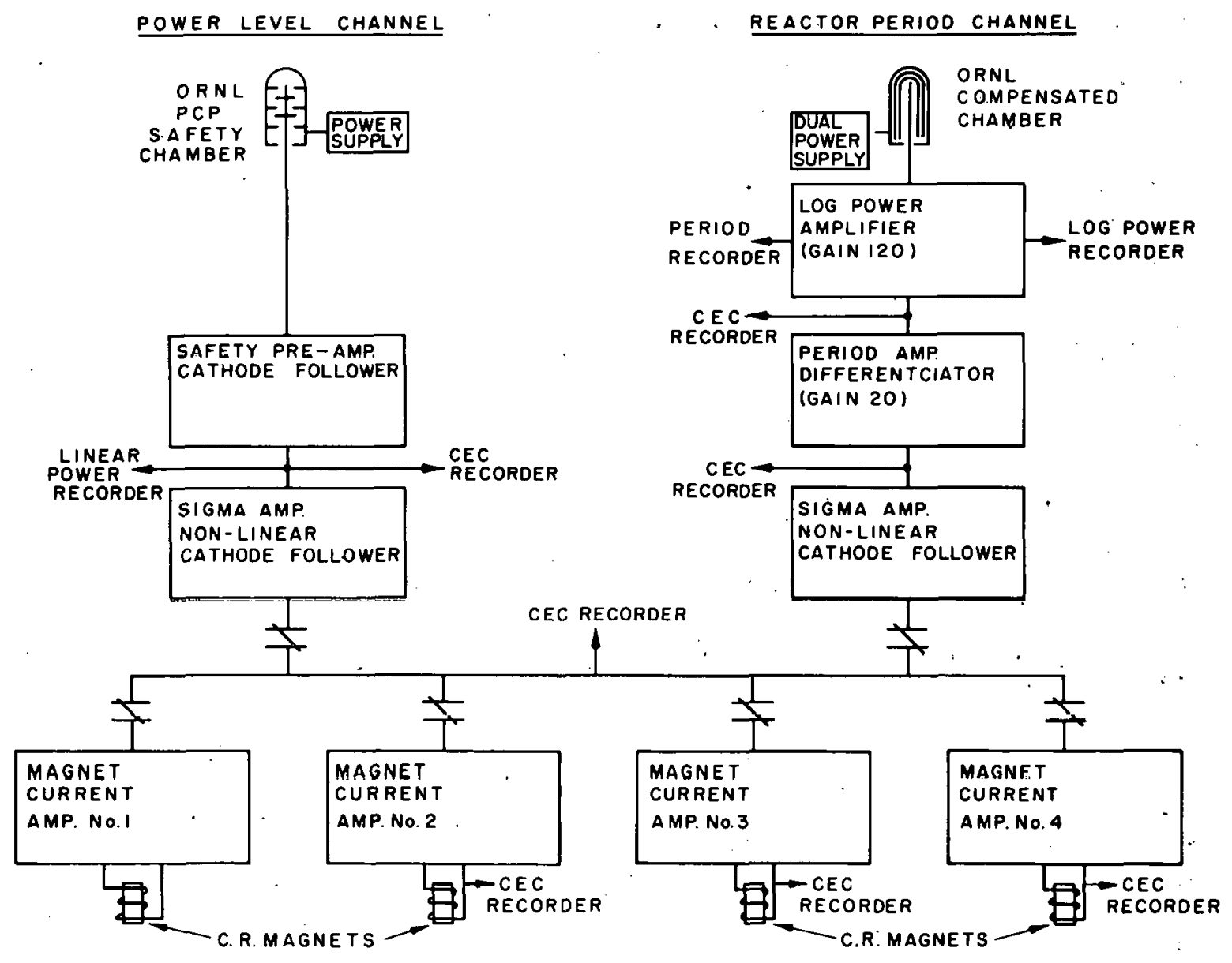

Fig. 4 BSR-II safety system for the Spert installation.

with a total U-235 mass of $6140 \mathrm{~g}$. By means of the period method, control rod calibration for one-, two-, and threerod ganged configurations were obtained over the full 14-in. range of rod travel. For the one-rod calibrations, the remaining three control rods were held fixed at 13.5 in. and a boron solution was used as a reactivity shim. The single-rod calibration for the $6070-\mathrm{g}$ core is shown in Figure 6, and that for the $6140-\mathrm{g}$ core is shown in Figure 7. The slight difference in the excess reactivity at 14 in. is attributed to the slightly heavier loading of the latter core. In Figure 8 the two-rod calibration for the $6070-g$ core is shown; for this calibration one rod was held at 13.5 in. and the remaining rod was used to compensate for the movement of the two-rod gang. The three-rod calibration for the 6070-g core is shown in Figure 9. For this

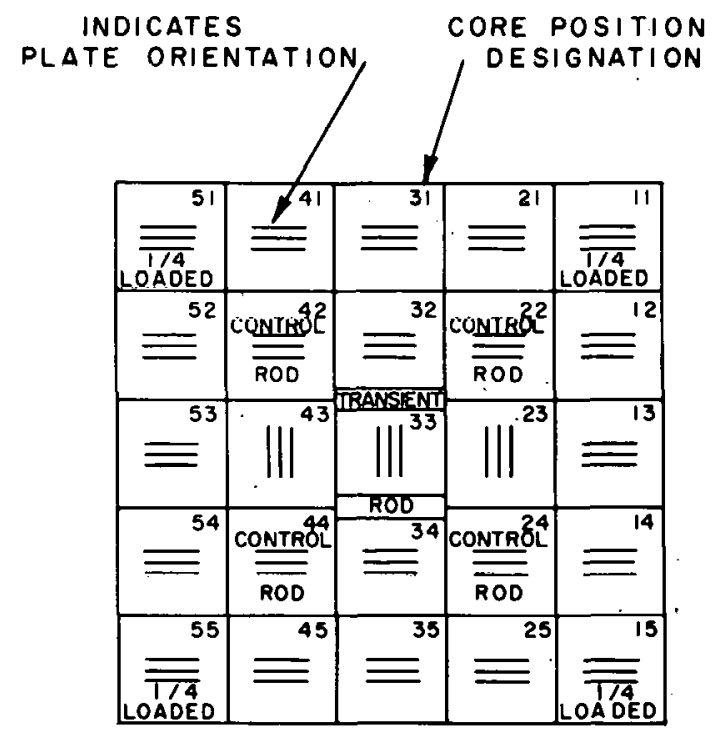

Fig. 5 BSR-II core configuration (6070-g loading) in Spert I. 


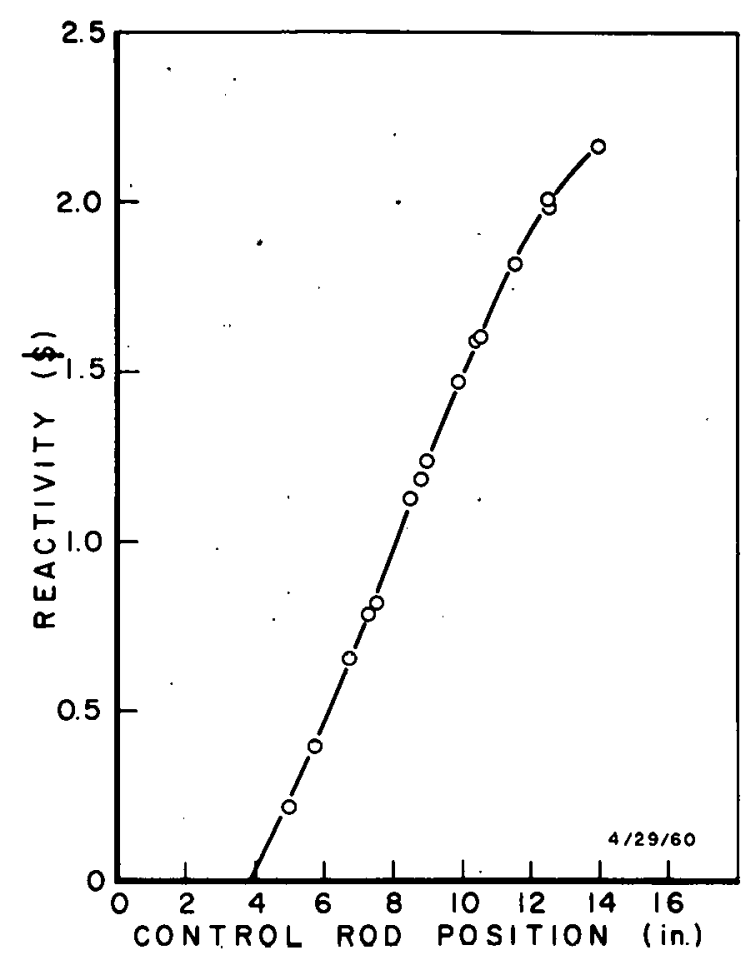

Fig. 6 Integral worth of single control rod in 6070-g BSR-II core.

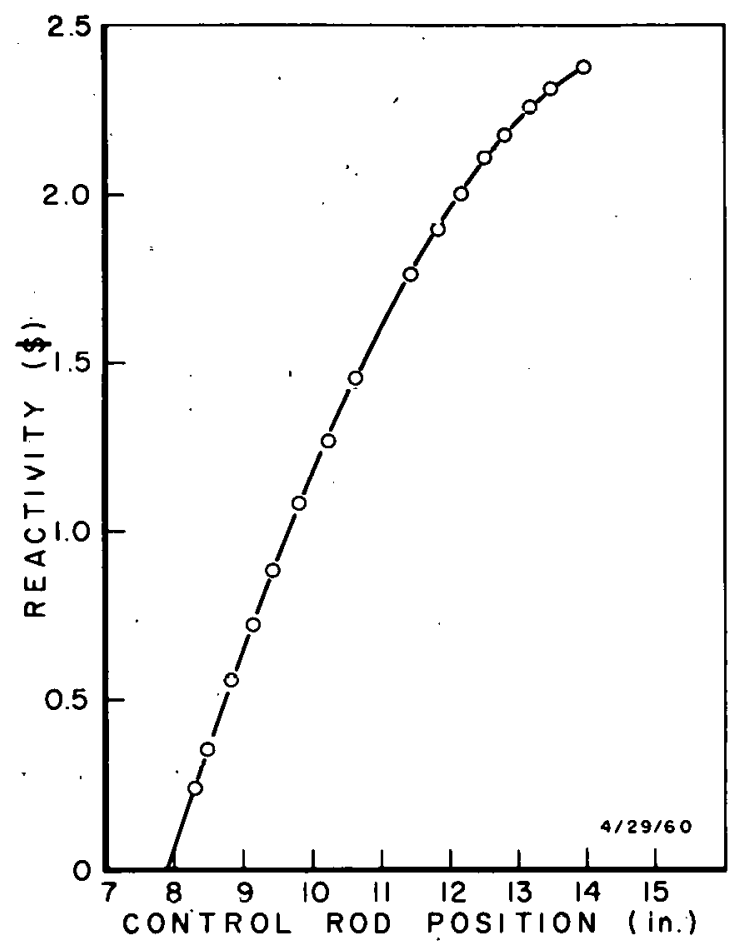

Fig. 8 Integral worth of two control rods in fก $7 \cap=g$ BSR-II core.

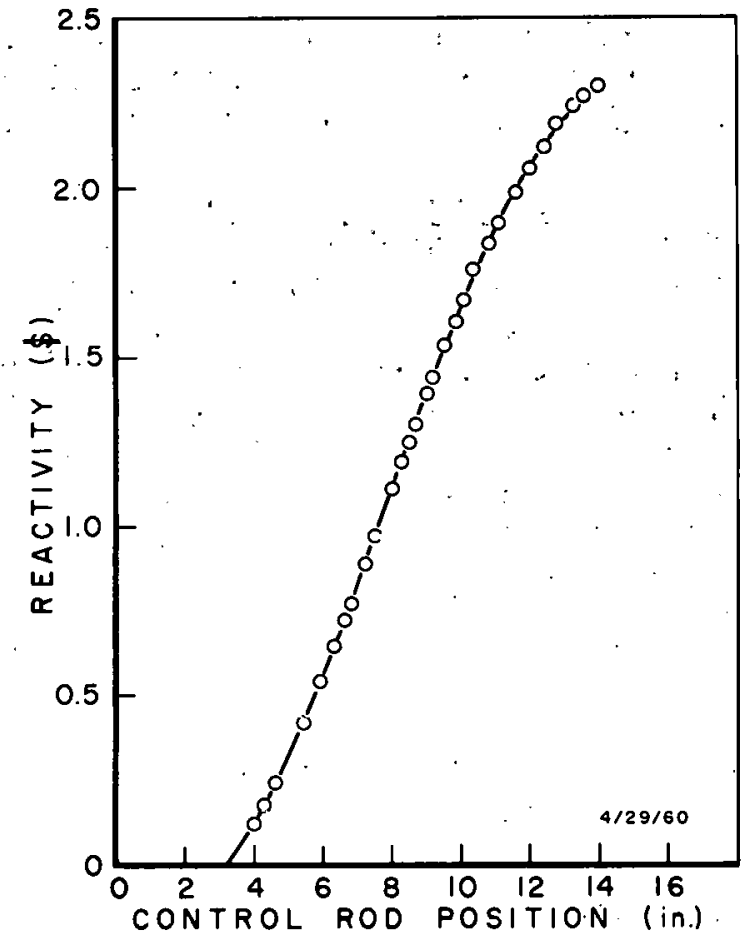

Fig. 7 Integral worth of a single control rod in 6140-g BSR-II core.

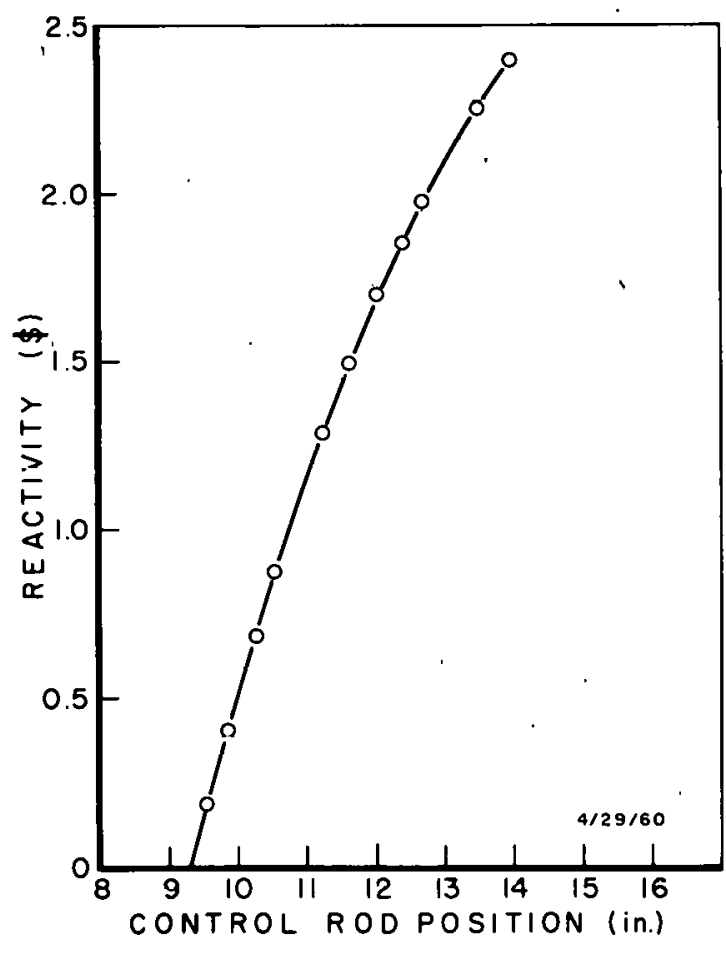

Fig. 9 Integral worth of three control rods in $0070=y$ BSR-II cure. 
calibration the change in position of the three rods was compensated by changing the position of the fourth rod.

2. Neutron Flux Distribution. Neutron flux distributions throughout the core were determined from activation measurements of bare and cadmiumcovered uranium-aluminum alloy foils. The uranium-aluminum alloy foils used were 0.005 in. thick $\times 5 / 32$ in. in diameter. Since only the relative flux distribution was desired, no attempt was made to determine the absolute nvt power from the foil irradiations.

The arrangement of the foils for this experiment is shown in Figure 10. The three parallel lines in each assembly position show the orientation of the fuel plates. On the basis of the geometric symmetry of the core, foil irradiations were made in only one quadrant of the core.

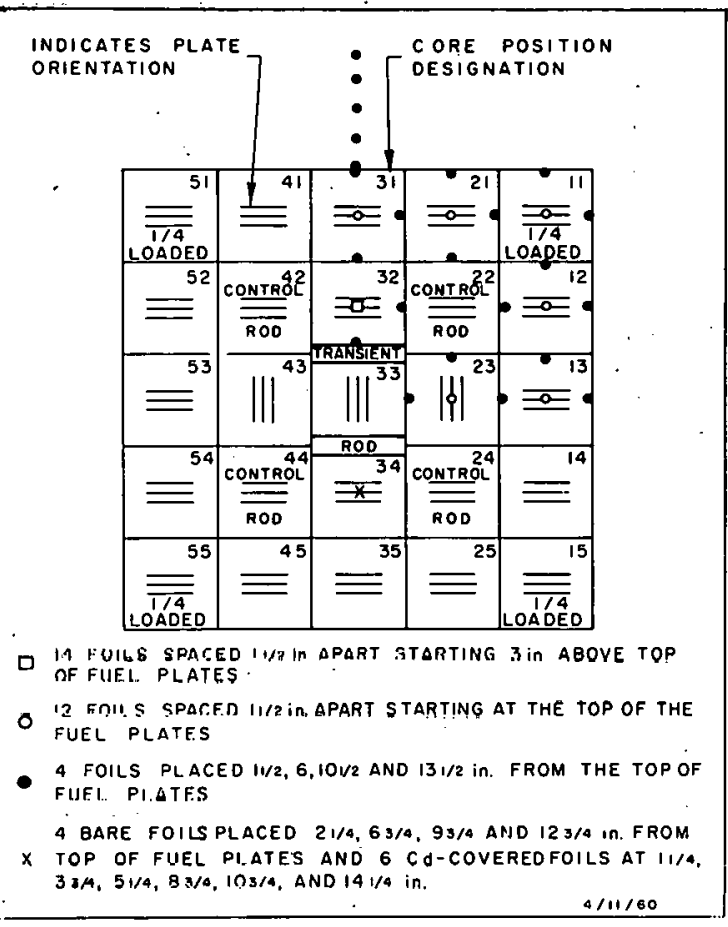

Fig. 10 BSR-II core configuration showing location of foils for flux measurements.

The presence of the rod drives prevented installation of foils in the control rod and transient rod assemblies. The uranium-aluminum foils were taped to plexiglass strips, which were inserted between fuel plates in the positions

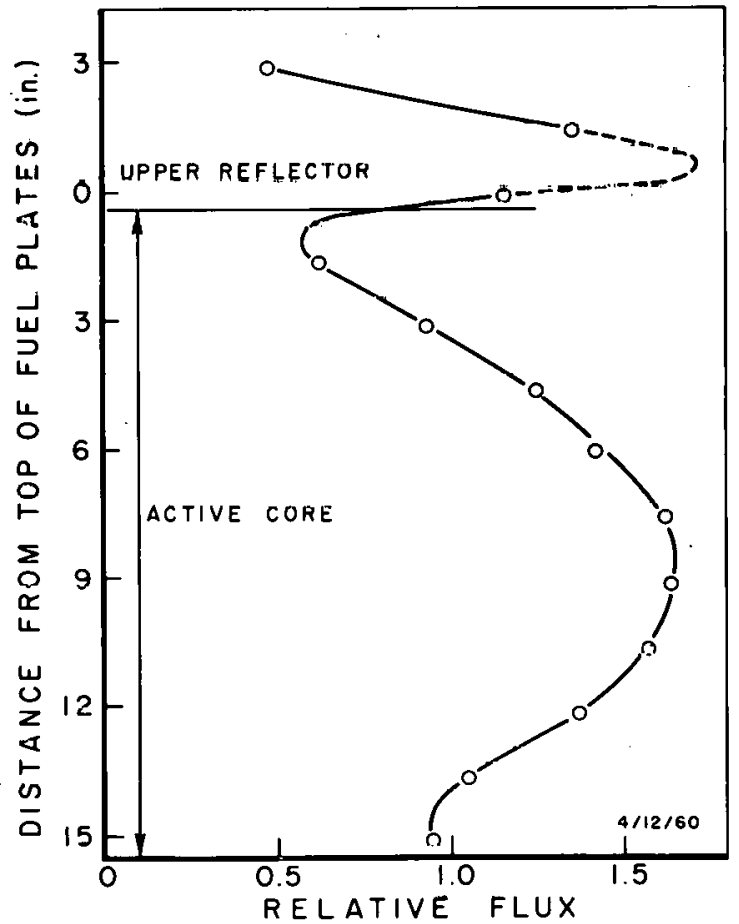

Fig. 11 Vertical flux distribution in center of assembly position 32 . indicated in Figure 10. The vertical positions of the foils also are indicated in Figure 10.

The vertical flux distribution in the center of a fuel assembly is shown in Figure 11. The cadmium ratlo was measured in the fuel assembly in position 34 , a position symmetric to 32 . This measurement indicated that approximately $14 \%$ of the fissions are caused by neutrons with energy greater than the cadmium cutoff energy.

The curves in Figure 12 show horizontal flux profiles through fuel assembly positions 11,21 , and 31 , parallel to the plane of the fuel plates. The vertical dashed lines in the figure indicate the boundaries of the fuel regions. The flux peaking between fuel assemblies is quite apparent. The flux is higher in assembly position 11 than in 21 , although 11 is a corner position. The higher flux is expected since the 
corner assemblies have only one-fourth the fuel density of the other assemblies.

Figure 13 shows the measured horizontal flux distributions through the center of assembly positions 13 and 23 . The curves have been extrapolated into transient rod assembly position 33 .

Figure 14 shows the horizontal flux distributions through the center of assembly positions 33,32 , and 31 and the adjacent reflector region. The flux peak in the reflector is twice the flux peak in the center of the core. Because of the peak in the reflector flux, the flux at the outside of the outer fuel plate of the assembly in position 31 is $25 \%$ higher than the flux at the inside of the same plate.

A flux peak also exists in the region of the transient rod guide box (Figure 13). This peaking probably is caused by the presence of the water channel around the transient rod.

In Figures 10 through 14 the relative flux values have been normalized such that the core average flux is 1.0 .

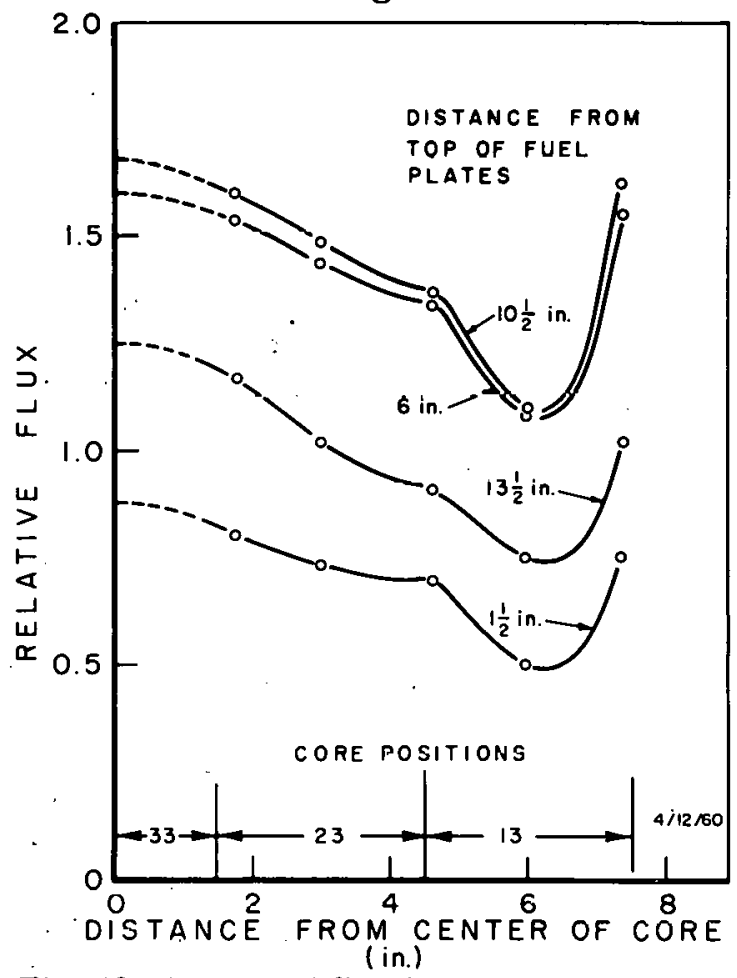

Fig. 13 Horizontal flux distributions through assembly positions $\mathbf{3 3}, 2.3$, and 13 .

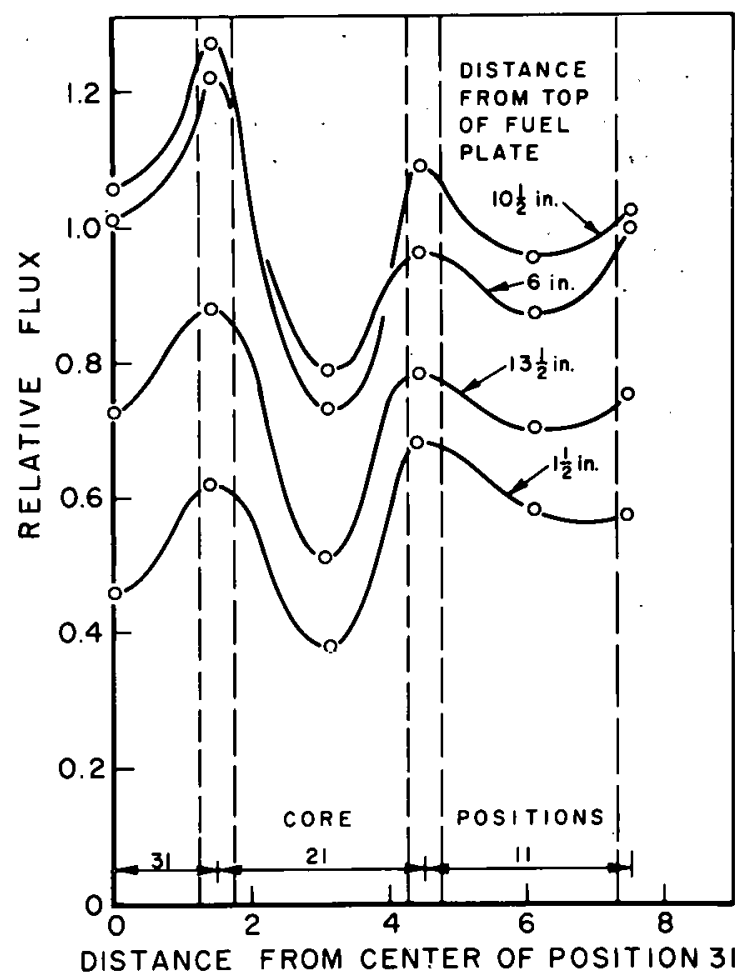

(in.)

Fig. 12 Horizontal flux distributions through assembly positions 31,21 , and 11 .

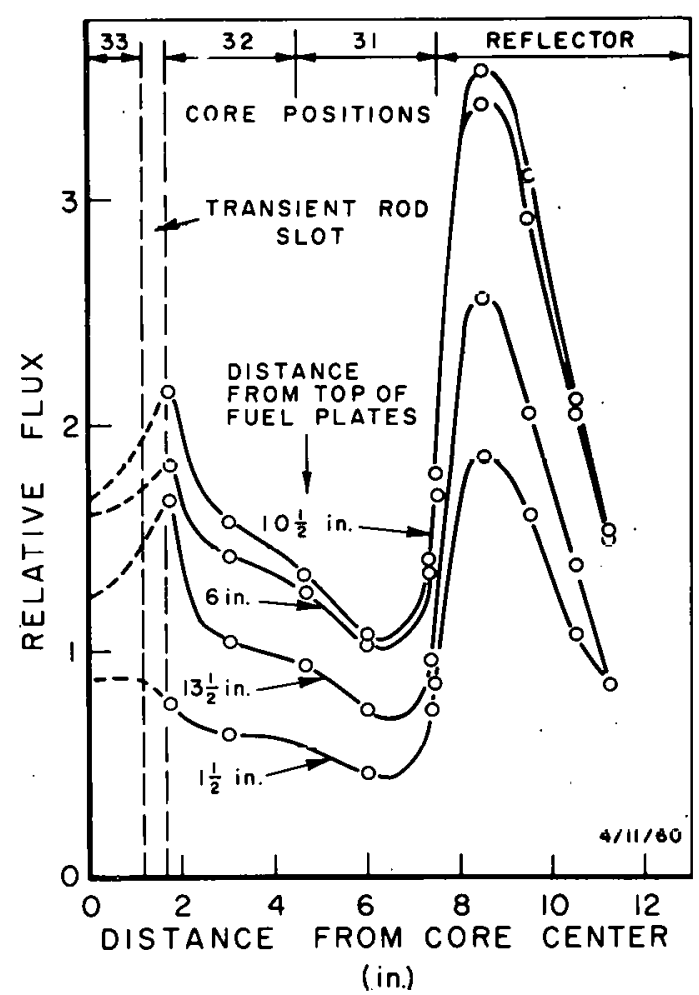

Fig. 14 Horizontal flux distributions through assembly positions 33,32 , and 31 and adjacent refleotor rcgiono. 
3. Is othermal Temperature Coefficient Measurement. The temperature coefficient of reactivity of the BSRII core was measured over the temperature range of 15 to $85^{\circ} \mathrm{C}$ with isothermal conditions existing throughout the reactor at the time of each reactivity measurement. The reactivity change corresponding to a change in temperature was determined from the change in critical position of the calibrated control rods. The temperature defect over the temperature range of the experiment is shown in Figure 15. The change in reactivity as the temperature of the reactor was increased was negative throughout the range of the experiment. Extrapolation of the data to boiling indicated the reactivity loss from $15^{\circ} \mathrm{C}$ to boiling to be 1.20 dollars.

4. Void Coefficient Measurement. The average void coefficient in the $6070-\mathrm{g}$ core loading shown in Figure 5 was measured using pure magnesium (0.2\% manganese impurity) strips, 0.11 in. thick $\times 0.52$ in. wide $\times 15$ in. long, to simulate voids. The reactivity worth of the simulated voids was measured for various void volumes up to approximately $4 \%$ of the core moderator volume. In these measurements the magnesium strips were distributed uniformly in all

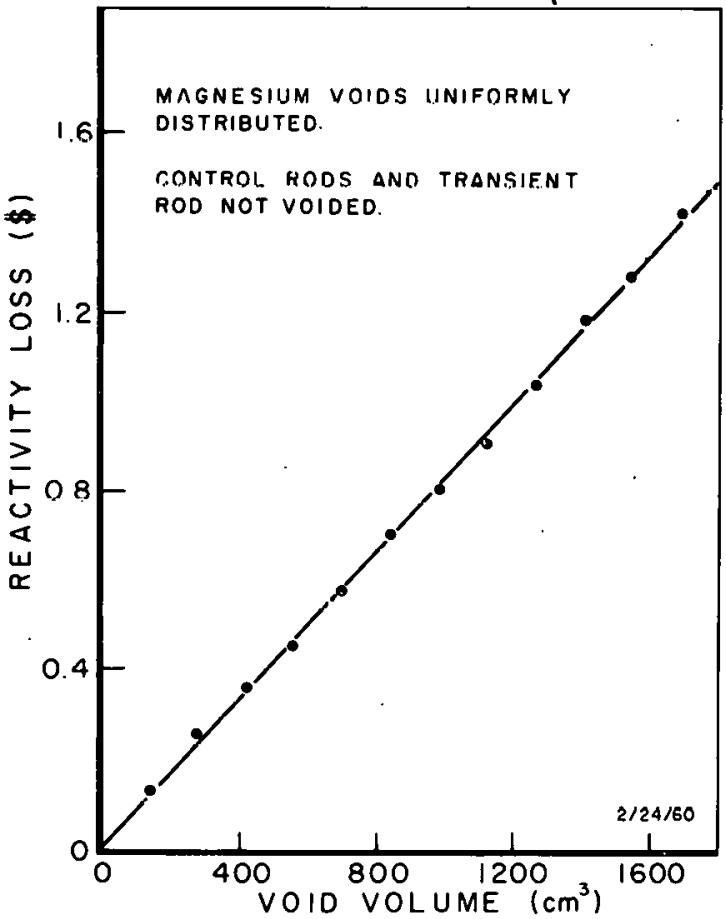

Fig. 16 Reactivity loss vs void volume for BSR-II core in Spert I.

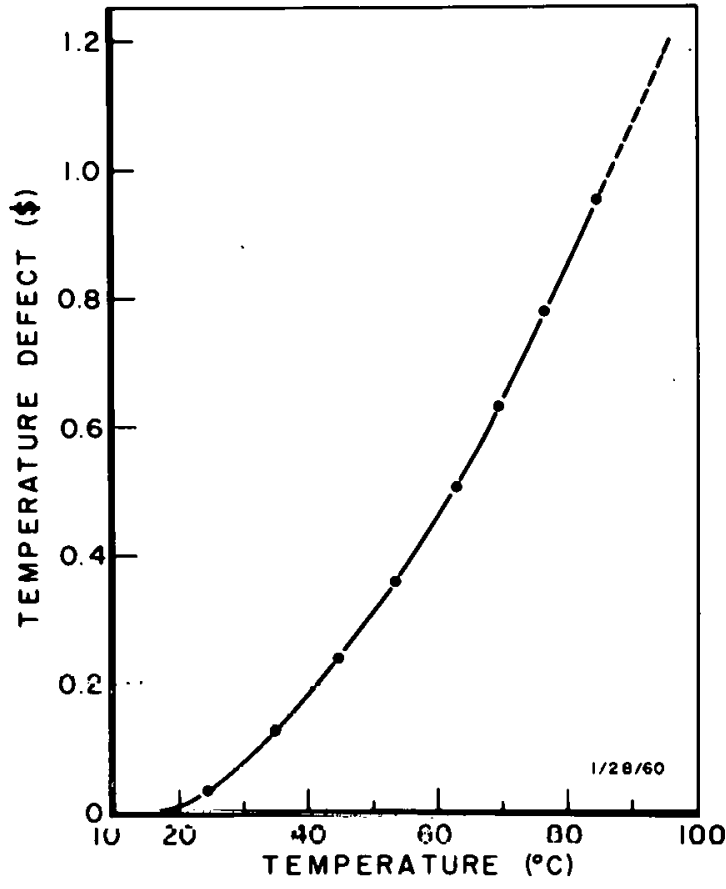

Fig. 15 Temperature defect vs temperature for BSR-II core in Spert I. fuel assembly positions except the transient rod and the four control rod assemblies. These positions could not be used because of mechanical interference with the insertion and removal of the strips. The effective coefficient determined for this distribution of voids was $8 \times 10^{-4} \$ / \mathrm{cm}^{3}$. Figure 16 shows the reactivity change as a function of void volume for these measurements. The reactivity change is seen to be linear with void volume to at least $1700 \mathrm{~cm}^{3}$ (approximately 4\% of the moderator core volume).

In order to estimate the effect of voids in the control rod assemblies, separate measurements were made of the reactivity worth of the void strips in the fucl assembly positions surrounding the transient and control rod assemblies. The data were then interpolated to obtain the worth of voids in these assemblies. The void coefficient 
representative of the uniformly voided core was calculated using the sum of the interpolated reactivity worths in the control and transient rod assemblies and the measured worth of void uniformly distributed in the remainder of the core. The resultant average void coefficient for magnesium strip was $11 \times 10^{-4} \$ / \mathrm{cm}^{3}$.

A comparison was made between the reactivity worth of the magnesium voids and styrofoam voids. Previous comparisons of styrofoam voids and true air voids had indicated that styrofoam voids are a good simulation of air. The volume of air in the styrofoam was determined by weighing an immersed assembly with and without the voids and calculating the displaced volume. One fuel assembly was voided, first with styrofoam and then with an equal volume of magnesium. The reactivity worth of the styrofoam was 1.3 times that of the magnesium. When this correction is applied to the above data, the average void coefficient for a uniform distribution of air voids is $14 \times 10^{-4} \$ / \mathrm{cm}^{3}$ or $0.6 \$ / \%$ void on the basis of a core moderator volume of $4.2 \times 104 \mathrm{~cm}^{3}$. 


\section{TRANSIENT TESTS}

\section{A. Introduction}

The primary purpose of the kinetic tests of the Spert BSR-II core was to compare the effectiveness of a fast mechanical safety system with that provided by the inherent characteristics of the core for limiting reactor power excursions. This comparison was obtained by subjecting the reactor to step-wise insertions of reactivity with and without the safety system in operation with the resulting powers, energy releases, fuel plate surface temperatures, and transient pressures compared as a function of reactor period. The tests that were performed without the safety system in operation are termed "self-limiting" tests, and those performed with the safety system in operation are termed "mechanical shutdown" tests. Three types of mechanical shutdown tests were performed in which either the reactor power level or the reactor period was used as a basis for initiating the insertion of the control rods:

(1) Power level scram tesls, in which power excursions were terminated by scramming the control rods when the power rise reached some presel linit

(2) Reactor period scram tests, in which power excursions were terminated by scramming the control rods when the period of the reactor power rise reached some preset limit

(3) Rod-reversal tests, in which control rods were rapidly inserted into the core by means of rod drive mechanisms when the power level reached a preset limit

In addition to these mechanical shutdown tests, transient tests were performed with no external neutron source present in the core. The purpose of these tests was to determine if any significant time delay occurs in establishing a continuing neutron chain following a step insertion of reactivity when the initial neutron population in the core is very low. An additional test was performed in which the control rods were withdrawn it the maximum rate, with no external neutron source in the reactor, in order to simulatc a possible start-up type sccident. For this test, both the power level and period circuits of the safety system were in operation and the resulting power excursion was suceessfully limited without damage to the reactor.

\section{B. Self-Limiting Transient Tests}

The tests in this category were performed with the safety system inoperative and can be described as self-limiting power excursions initiated by stepwise insertions of reactivity. The response of a reactor to sudden reactivity additions depends on the magnitude and rate of the reactivity insertion, the prompt neutron lifetime, and the various reactivity compensating mechanisms of the reactor. Following a step insertion of reactivity in plate-type cores such as the BSR-II, the reactor power will rise exponentially with a characteristic period until the energy of the excursion acting through various shutdown Inechallisins causce the power to reach a maximum and seek some lower equilibrium level. The various shutdown mechanisms occur according to the amount and the rate of energy release, as well as the heat transfer properties of the reactor which regulate the amount and rate of fuel plate expansion, moderator expansion, and formation of steam voids. The compensated reactivity necessary to limit the power burst can be equal to or much less than the initial 
inserted reactivity. For the BSR-II core, the compensated reactivity at peak power in the region of reactor periods from $10 \mathrm{sec}$ to $100 \mathrm{msec}$ exhibits a maximum of about 20 cents for reactor periods of about $1 \mathrm{sec}$ and a minimum of about 10 cents for reactor periods near prompt critical. Above prompt critical, the required compensating reactivity at peak power is approximately equal to the prompt reactivity insertion.

Self-limiting tests were performed with reactor periods from $1 \mathrm{sec}$ to 15 msec. Transient tests performed on similar Spert stainless steel plate-type cores $[6,7]$ showed that rippling of the fuel plates occurred for roughly $10-\mathrm{msec}-$ period tests. To determine the onset of this type of damage, fuel assemblies in the positions of highest neutron flux were removed and inspected after each power excursion for periods less than $50 \mathrm{msec}$. Inspection of the fuel assemblies after the $15-\mathrm{msec}$-period test indicated the onset of fuel plate rippling.

The peak power for the 15-msec test was $215 \mathrm{Mw}$, with an energy release up to the time of peak power of $4 \mathrm{Mwsec}$, and an energy release up to the time of scram of $5.6 \mathrm{Mwsec}$. The highest measured fuel plate surface temperature in the core' was $112^{\circ} \mathrm{C}$ at the time of peak power and reached a maximum of $184^{\circ} \mathrm{C}$ about one period later. The steepest rate of rise in fuel plate surface temperature, which occurred immediately before saturation temperature of the moderator, was $7.6^{\circ} \mathrm{C} / \mathrm{msec}$. The maximum measured pressure of $6.3 \mathrm{psig}$ occurred after the power peak at the time when the fuel plate surface temperature was about maximum. As a result of the observations made during this test and subsequent fuel inspection an upper power limit of $200 \mathrm{Mw}$ was established for all future power bursts in the test series and self-limiting tests were not extended to periods' shorter than $15 \mathrm{msec}$.

The self-limiting transient test results of burst shape behavior, peak power, and fuel plate temperature were similar to the results obtained on aluminum and stainless steel plate-type cores previously tested at Spert $[8,9,10]$. Because of the similarity of the core properties, the results of the BSR-II tests were in closest agreement with those of the Spert $P$ core. Peak power as a function of reciprocal period, and maximum fuel plate temperature as a function of reciprocal period for the BSR-II and the $P$ cores are shown in Figures 17 and 18, respectively. On the basis of the similarity of these data in the reactor-period range from $1 \mathrm{sec}$ to $15 \mathrm{msec}$ (the reactorperiod range of the BSR-II self-limiting tests) extrapolation of the BSR-II peak power data and maximum fuel-plate surface-temperature data to shorter periods was made. Fuel plate surface temperature at the time of peak power as a function of reciprocal period, and energy released to the time of peak power as a function of reciprocal period

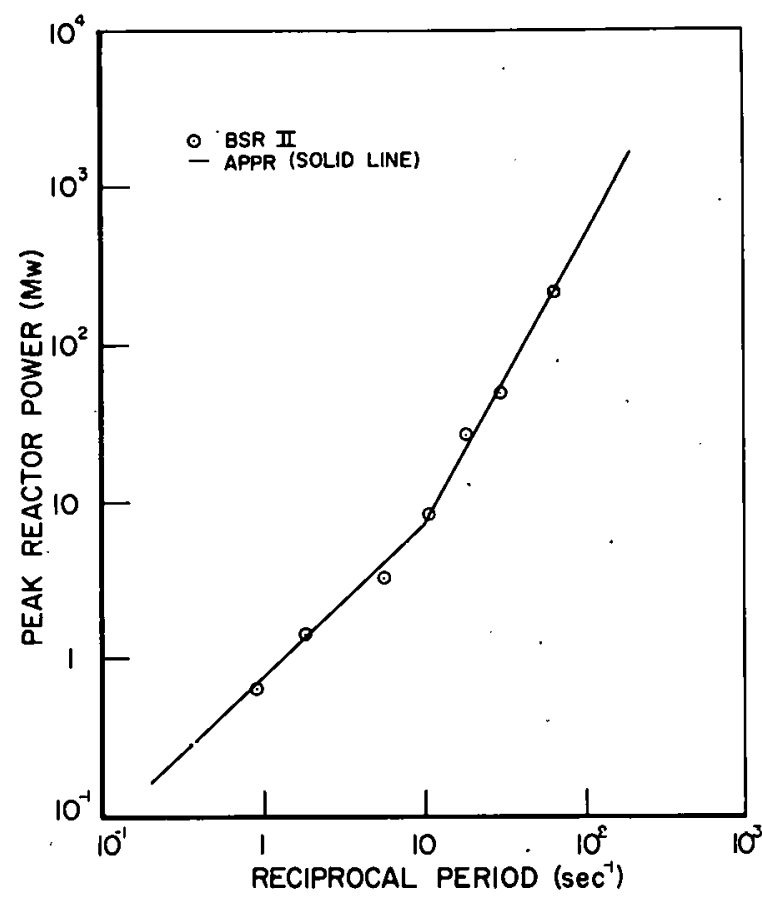

Fig. 17 Peak power vs reciprocal period for BSR-II and P("APPR") cores (self-shutdown tests). 


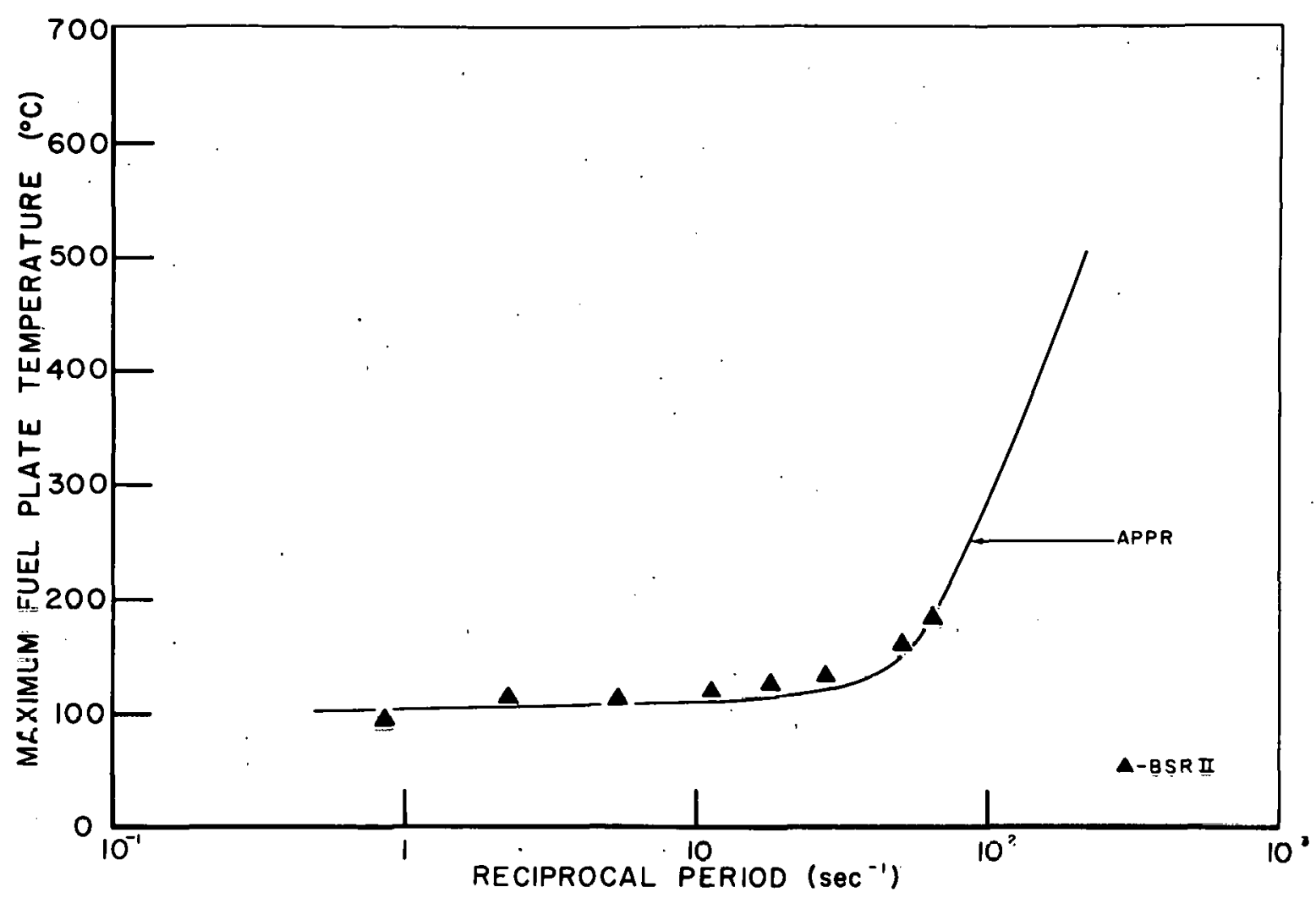

Fig. 18 Maximum plate temperature vs reciprocal period for BSR-II and P("APPR") cores (selfshutdown tests).

for the two cores are shown in Figures 19 and 20, respectively. These data show that the energy release necessary to limit the burst in the region above prompt critical for the two cores is in close agreement, although the $\mathrm{P}$ core required more energy release for shutdown than the BSR-II in the region below prompt critical. The maximum fuel plate surface temperature at the time of peak power showed close agreement between the two cores above prompt critical while the $\mathrm{P}$ core attained higher temperatures below prompt critical, as would be expected from the energy release data. Time plots of power and fuel plate temperature for the self-limiting tests are included in Appendix A.

\section{Safety System Tests}

The effectiveness of the BSR-II safety system and other similarly designed reactor control systems in limiting reactor transients depends on (a) the electromechanical delay time between the surpassing of preset power level or reactorperiod limit and the initiation of the control rod movement, and (b) the time required for sufficient negative reactivity to be inserted to limit the power burst.

To increase the rate at which negative reactivity can be added to the reactor system, compressed springs are used in the BSR-II to provide the low-mass control rods with an initial acceleration of approximately six times the acceleration due to gravity. For the BSR- $\Pi$ i safety system, the time between the surpassing of a preset limit and the release of the control rods by the magnets is approximately $5 \mathrm{msec}$. This is considered to be close to the minimum delay time that can be presently attained in a system using magnetically coupled control rods. 


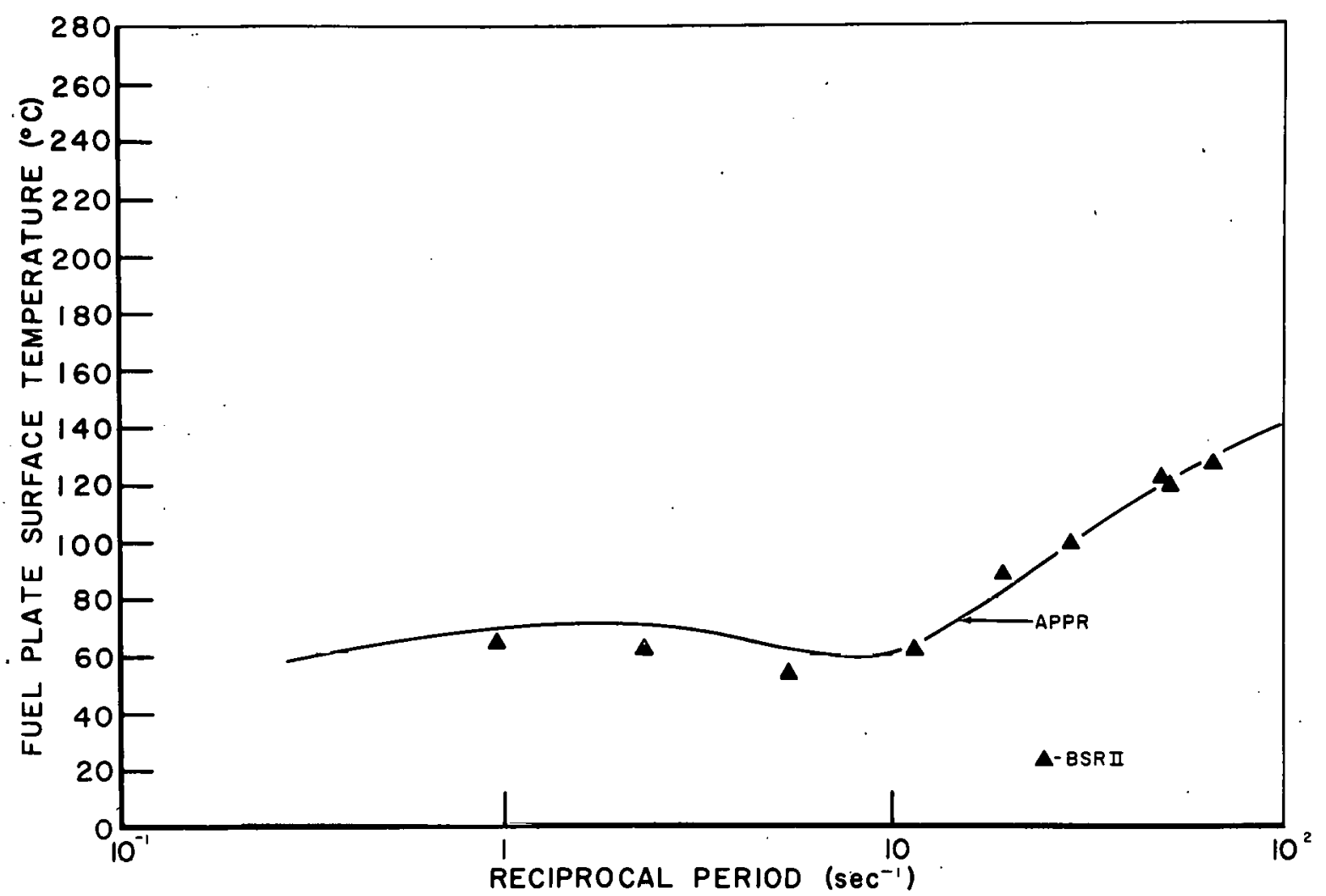

Fig. 19 Fuel plate surface temperature at the time of peak power vs reciprocal period (self-shutdown tests).

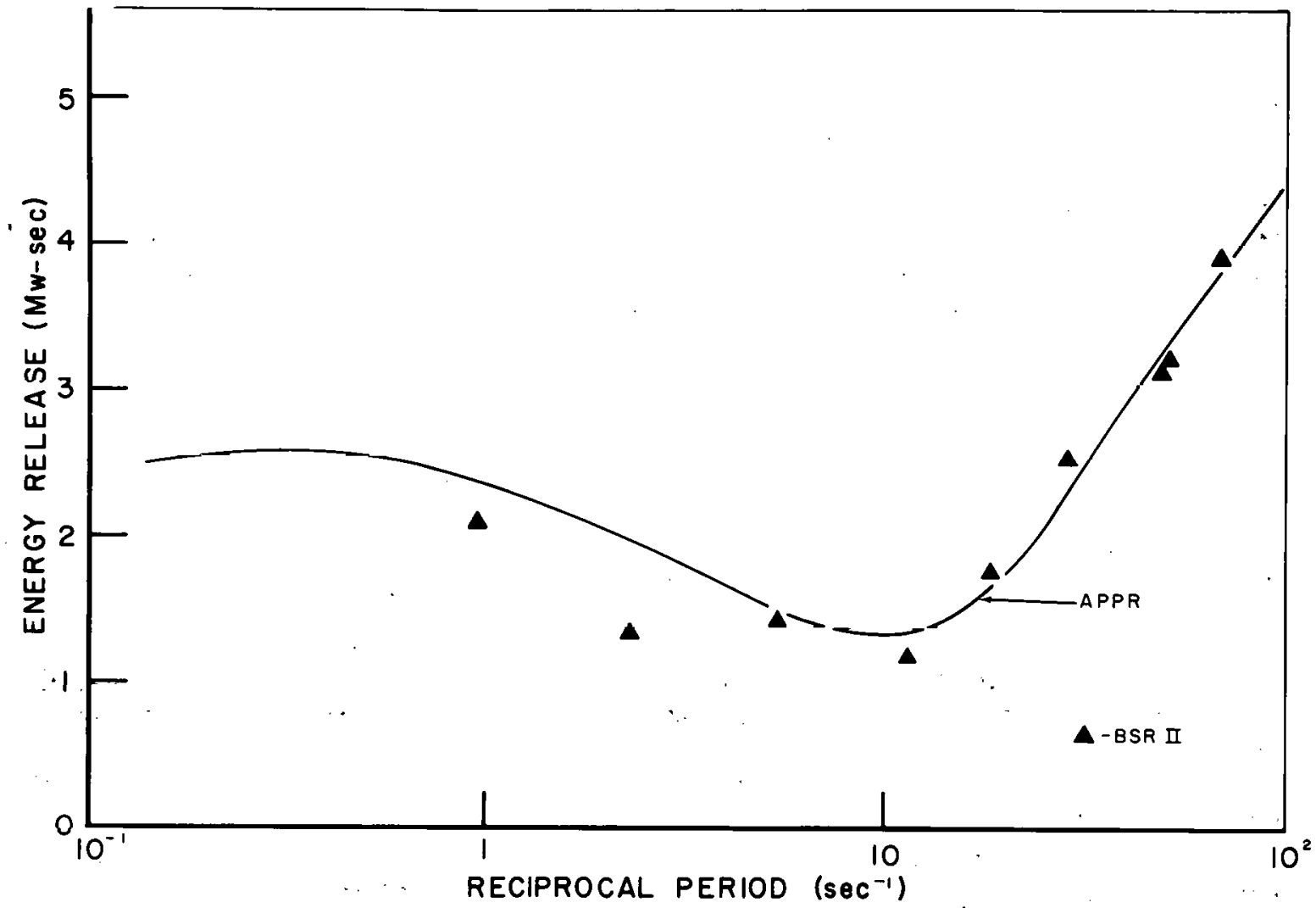

Fig. 20 Energy release to the time of peak power vs reciprocal period (self-shutdown tests). 
For the transient tests involving the safety system, three control rods were raised to 13.5 in. and kept at that position until released for the purpose of limiting a power burst. The fourth control rod was used as a reactivity shim and was not released for shutdown purposes except in a few tests.

1. Power-Level Scram Tests. A series of tests was performed to determine the effectiveness of the BSR-II power-level scram system under accident conditions. In these tests, the reactor was subjected to stepwise insertions of reactivity ranging from 1.0 to 1.5 dollars and the resulting power excursions were limited by the power-level scram system. In each of these tests, the safety system was set to scram a predetermined number of control rods when the power level reached $100 \mathrm{kw}$. In addition, the effect of the negative reactivity insertion rate was demonstrated by varying the number of control rods that were scrammed. For the 1.5-dollar reactivity insertion test, the initial reactor period was $5 \mathrm{msec}$, with the power approaching the upper limit of $200 \mathrm{Mw}$ previously set for this core. Figure 21 shows the maximum power reached during these level scram tests as a function of the reciprocal reactor period for 2,3 , and 4 control rod shutdowns.

2. Period Scram Tests. The addition of a period scram circuit to a level scram safety system provides increased protection, and, if the circuit is capable of sensing the reactor period at low power levels, the range of power excursions that can be safely limited can be extended to shorter periods. A series of power excursion tests was performed with both the period and power-level scram circuits in operation to determine the additional protection provided by the BSR-II period scram circuits. In each of these tests the safety system was set to scram three control rods for all reactor periods shorter than one second. The period circuit was capable of discriminating reactor periods shorter than one second at a power level of about one watt. The shortest period test of this system was a $2.9-\mathrm{msec}$ period, for which the power level approached the 200-Mw limit. The peak powers reached during these period scram tests as a function of reciprocal period are shown in Figure 21.

3. Comparison of Self-Limiting, Power-Level, and Period Scram Tests. In evaluating the relative merits of selflimiting shutdown and mechanical scram shutdown in the BSR-II core, the following may be noted from the data shown in Figure 21.

(1) The power-level-initiated scram is of considerable value in extending the range of power excursions to which the reactor can be subjected without resulting in damage.

(2) The period-initiated scram, set to operate at low power levels as in reactor

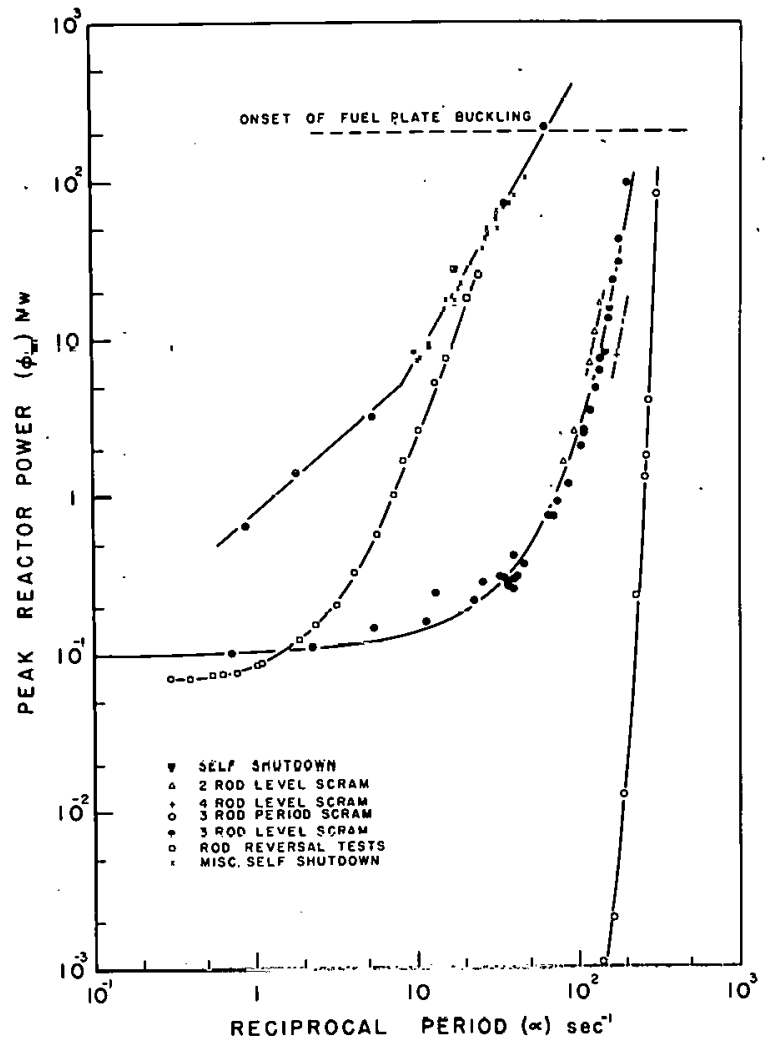

Fig. 21 Peak power vs reciprocal period for various modes of shutdown. 
start-up, is even more effective than the power-level-initiated scram.

(3) The rapid rise of the peak power curves obtained for the period and power-level scram tests indicate that they will eventually join the self-limiting shutdown curve for sufficient short reactor periods. Extrapolation of the data indicates that they will join near the region of core meltdown.

The conclusion that is drawn from these observations is that the power-level and period scram system will protect the reactor in the region of minor core damage, but offers no increased protection over self-limiting shutdown in the region of serious damage.

Since, for the BSR-II safety system, the delay time associated with the electronics and holding magnets is short compared with the shutdown reactivity insertion time, it appears that the greatest contribution to increasing the effectiveness of the safety system could be made by increasing the negative reactivity insertion rate. The negative reactivity inserted as a function of time by groups of 2 , 3 , and 4 control rods is shown in Figure 22. These reactivity insertions are for the control rods released from a height of $13.5 \mathrm{in}$. with an initial acceleration of $6 \mathrm{~g}$. The optimum condition for minimum reactivity-insertion time would be obtained when the control rods are released from, and allowed to travel through, their region of highest differential worth. The elapsed time from control rod release to the time of peak power as a function of reciprocal period is shown in Figure 23. From a comparison of the rod-drop speed and the control rod worth as a function of position, it was found that in some of the tests as much as $10 \mathrm{msec}$ of insertion time could be saved by releasing the rods from a height of about 9 in. withdrawn.

Time plots which compare the transient power obtained during mechanical shutdown and self-shutdown tests are given in Appendix B.

4. Rod Reversal Tests. Under certain reactor operating conditions it may be desirable to have a safety system arranged to initiate the insertion of the control rods with the control rod drive mechanisms rather than by initiating a control rod scram. A safety system could be used in this manner when the reactor is operating at a steady power level with the power-level reversal circuits set slightly above the operating power, or during the rise to the operating power level with the period circuits set to insert the rods for all periods shorter than some preset conservative value. The effectiveness of this rod-reversal type of shutdown depends primarily on three factors: (a) the power level at which the system is actuated, (b) the system delay times, and (c) the insertion rate of shutdown (negative) reactivity.

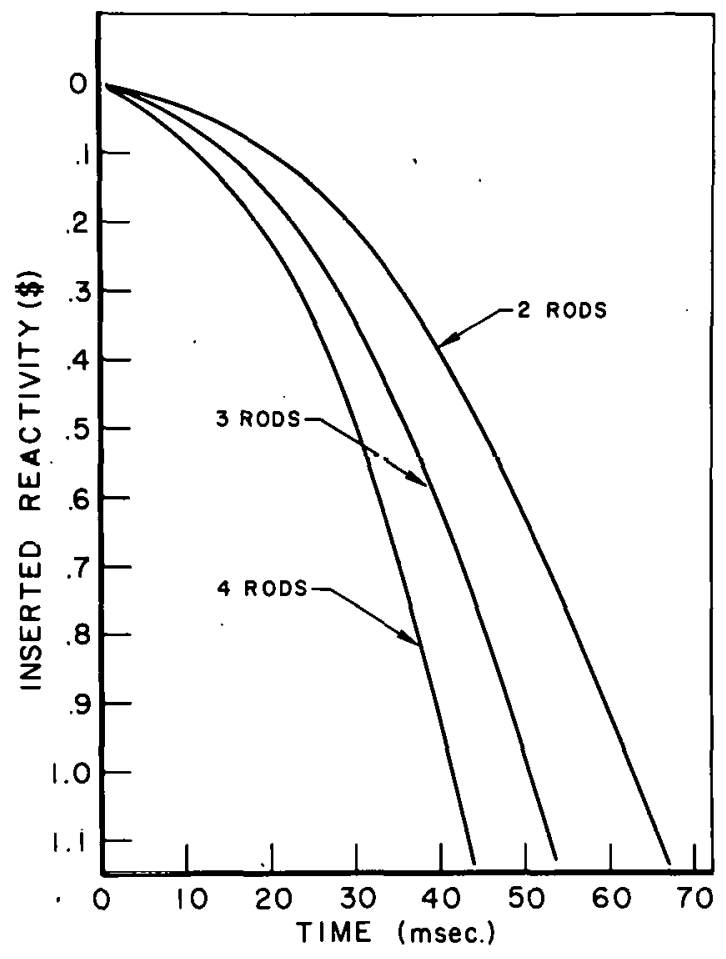

Fig. 22 Insertion rate of reactivity for various groups of control rods. 


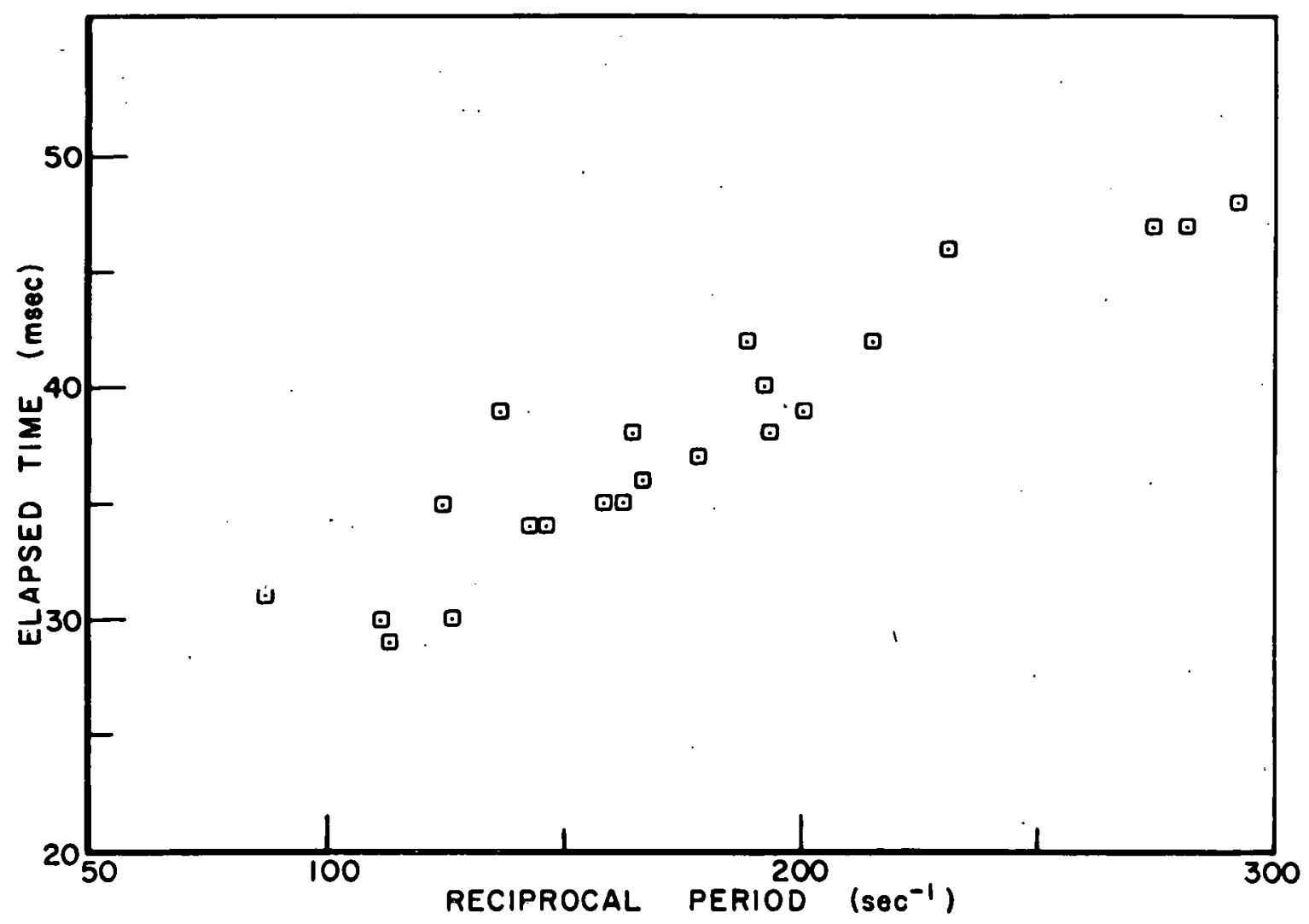

Fig. 23 Elapsed time from rod release to the time of peak power vis reciprocal period.

The BSR-II safety system is capable of reversing, or inserting, the control rods with the drive mechanisms on a signal from the power-level or period scram circuits. A series of tests was performed to determine the effectiveness of this mode of operation. For these tests, the power-level circuit was set to initiate control rod insertion at a power level of $70 \mathrm{kw}$ and the period circuit was not in operation. The tests were initiated by stepwise insertions of reactivity with the reactor subcritical at a power level of approximately one watt. This does not simulate the situation of a reactor operating at steady power which suddenly receives an addition of excess reactivity, but it does simulate an accident where the reactor is on a positive period at the time the power exceeds the preset limit, which is the condition of concern in these tests. The tests covered a range of reactor periods from $14 \mathrm{sec}$ to $40 \mathrm{msec}$. The delay between the time when the reactor power exceeded $70 \mathrm{kw}$ and the time that shutdown could be detected for each test was measured to be approximately $90 \mathrm{msec}$. The insertion rate of negative reactivity for the four control rods starting their downward movement from the operational position (about $10 \mathrm{in.} \mathrm{withdrawn)} \mathrm{was}$ $0.17 \$ / \mathrm{sec}$.

The peak powers that were reached during these tests as a function of reciprocal period are shown in Figure 21. Comparing the peak power data for the rod-reversal tests with the peak power for self-shutdown tests, it can be seen that rod-reversal shutdown is more effective than self-shutdown for periods longer than approximately $40 \mathrm{msec}$. For shorter periods, the rodreversal curve approaches the self-shutdown curve asymptotically as the self-shutdown contribution to the overall shutdown of the system increases relative to the rod-reversal contribution. 
In the rod-reversal tests the shutdown reactivity is provided by the insertion of the control rods and by the heat transfer to the cladding and moderator. The latter is dependent on the amount of energy release and the heat transfer rates: In general, for highly enriched, plate-type cores nearly all of the energydependent shutdown reactivity is developed in the last decade of power rise before the power peak. In the region of reciprocal period from 0.8 to $4.0 \mathrm{sec}^{-1}$, the peak powers for the rod-reversal tests were more than a decade below those obtained from self-limiting tests. Therefore, in this region the shutdown reactivity can be attributed essentially to that provided by insertion of the control rods. For shorter periods, both the external and inherent shutdown effects contribute to limiting the power burst.

The instantaneous reactivity was calculated from the reactor kinetics equations using the experimental reactor power data as input; and the compensated reactivity was then determined from

$$
R_{c}(t)=R(t)-R(0)
$$

where,

$$
\begin{aligned}
R_{c}(t) & =\text { compensated reactivity at time } t \cdot(\$) \\
R(0) & =\text { initial reactivity }(\$) \\
R(t) & =\text { reactivity at time }(\$)
\end{aligned}
$$

The calculated compensated reactivity at the time of peak power $R_{c}\left(t_{m}\right)$ for the self-limiting and rod-reversal tests and the measured shutdown reactivity provided by control rod insertion up to the time of peak power are shown as functions of the reciprocal period in Figure $24 . R_{c}\left(t_{m}\right)$ is seen to be equal to the reactivity inserted by the control rods in the region where energy transfer contributes little to the overall shutdown, and is less than $R_{c}\left(t_{m}\right)$ in the region where inherent and external shutdown modes both contribute. Also, $R_{\mathbf{c}}\left(t_{m}\right)$ for the rod-reversal and self-limiting tests differs throughout the range of measurements and tends to approach the same value as the reactor period becomes shorter than prompt critical.

The difference in the amount of shutdown reactivity needed, in the region below prompt critical, to limit the power burst in the two types of tests demonstrates the importance of the rate at which the shutdown reactivity is inserted. The two sources of shutdown reactivity differ in an important manner in that the insertion rate of the shutdown reactivity by the control rods is essentially constant for all reactor periods, while that from the energy transfer increases rapidly with respect to time for a particular reactor period, and the rate of increase gets larger for shorter periods.

\section{Low-Level Start-Up Tests}

1. Introduction. A problem of some concern in the field of reactor safety is that reactivity could be added to a reactor system during start-up from a very low source level, which might significantly exceed safe limits before the power level is large enough for inherent reactivity compensating mechanisms to be effective or before detectable signals appear. This problem arises as a consequence of the low neutron population in the core and the statistical nature of the fission chain. Usually an external neutron source of sufficient strength is 


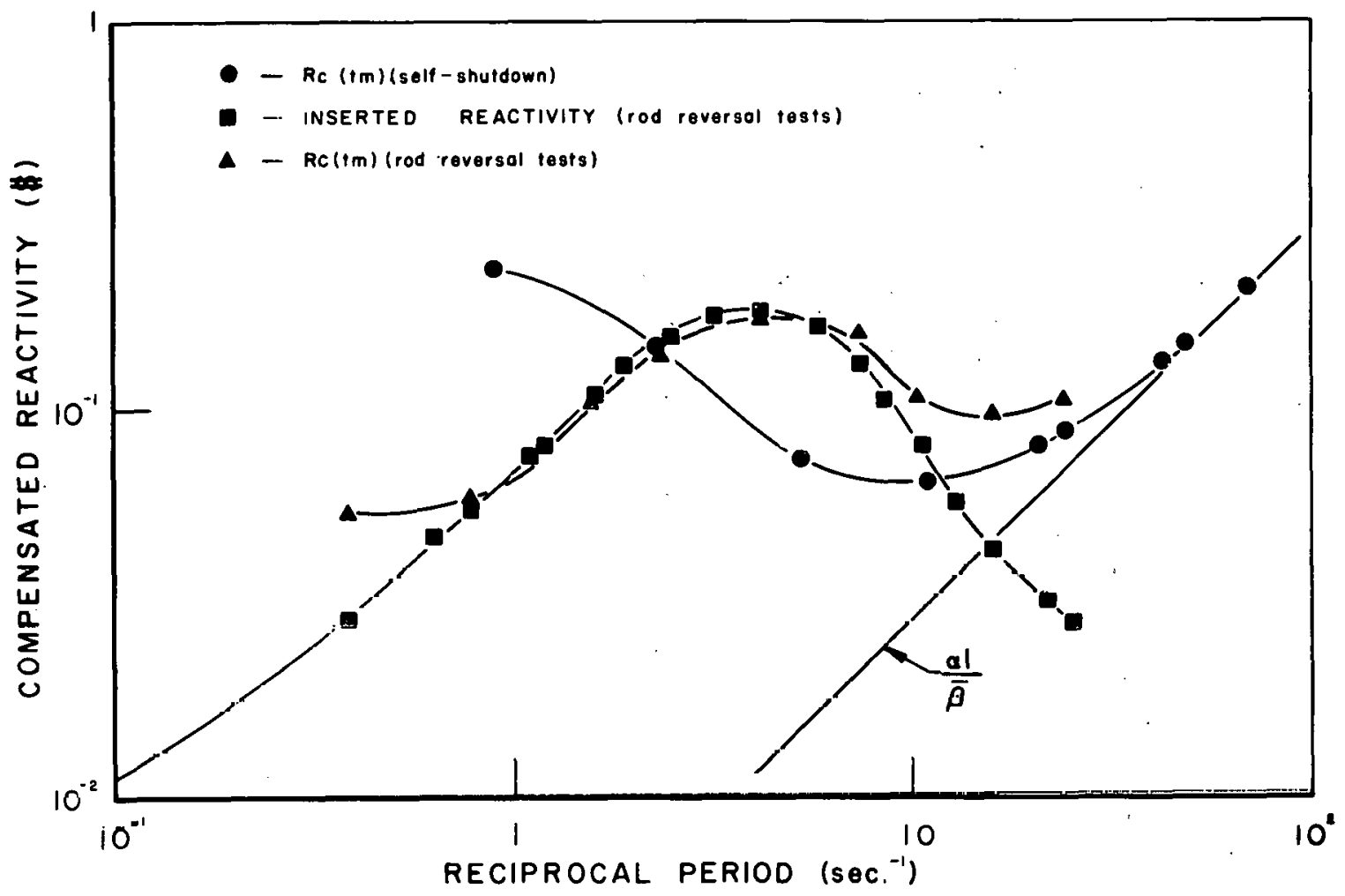

Fig. 24 Compensated reactivity and inserted reactivity vs reciprocal period.

placed in the core to eliminate this problem. The presence of the source ensures that a sufficient number of neutrons is available to allow the reactor power level and the reactivity to be monitored during the entire rise to the operating power level.

A series of experiments was performed with no external source in the reactor, in which the intrinsic neutron source level of the BSR-II was measured, the statistical delay in initiating a sustaining neutron chain was observed, and a start-up experiment was performed in which the control rods were withdrawn at the maximum available rate.

2. Intrinsic Neutron Source Level Measurement. The intrinsic neutron source in the new BSR-II core was determined by comparing the neutron counting rates at various multiplications, both with and without a calibrated radiumberyllium source having a strength of $1.5 \times 10^{3} \mathrm{n} / \mathrm{sec}$ in the core. The magnitude of the intrinsic neutron source $\mathrm{B}$ can be calculated from the following relationship:

$$
B=\frac{C_{0} S I}{C_{i}-C_{0}}
$$

where,

$\mathrm{C}_{\mathrm{i}}=$ neutron counting rate with the external neutron source in the core

$C_{0}=$ neutron counting rate with no external source in the core 
$\mathrm{S}=$ external neutron source strength

$I$ = importance factor.

The constant I, assumed to be unity here, arises from the fact that the intrinsic neutron source is a distributed source with a particular energy spectrum, while the external source is effectively a point source with a different energy spectrum. From this experiment it was determined that $500 \mathrm{n} / \mathrm{sec}$ can be used as a reasonable approximation for the BSR-II intrinsic source level.

3. Delay Time in Establishing Neutron Chains. Time delays in establishing continuing neutron chain reactions were observed in a series of power excursion tests in which the initial power level in the reactor was very low, of the order of $10^{-5}$ watts. Measurements were made of the elapsed time between the seating of the transient rod, which initiated the power excursion, and the attainment of a 100-kw power level. The time required for the power in a super-prompt critical reactor to rise on the measured asymptotic period from the estimated initial power level to $100 \mathrm{kw}$ was calculated and subtracted from the observed elapsed time. Negative values of the difference indicated that the power rise had been initiated before the rod was seated. Positive values indicate the possible existence of a delay time in the initiation of the power rise. The positive values are denoted "waiting time" and are shown in Figure 25 as a function of reciprocal period. While the complexity of the statistical problem prevents this waiting time from being identified as the delay time in initiating a continuing chain, the waiting time may be used as the effective time during which unwanted and undetected reactivity could be added to the reactor. The scatter in the data is in part due to the statistical nature of the delays, uncertainties in the actual starting power, and the calculational approach. It is evident from the data that in some tests considerable time delays did exist between the injection of reactivity and the attainment of a stable period. The waiting time as defined above and the rate of reactivity injection are determining factors in the potential hazards of reactor operations at very low power levels.

4. Start-Up Accident Test. A rapid continued withdrawal of the control rods from a new reactor containing no external neutron source could possibly result in a step-induced power excursion rather than a ramp-induced power excursion. For this to occur, the delay time in the initiation of a continuing neutron chain reaction must be long. If this delay is sufficiently long, rapid withdrawal of the control rods from a new, cold reactor, with no external source present and no indication of neutron level, may constitute a potential accident for many reactor systems.

This accident was simulated in the BSR-II by performing a "blind" start-up

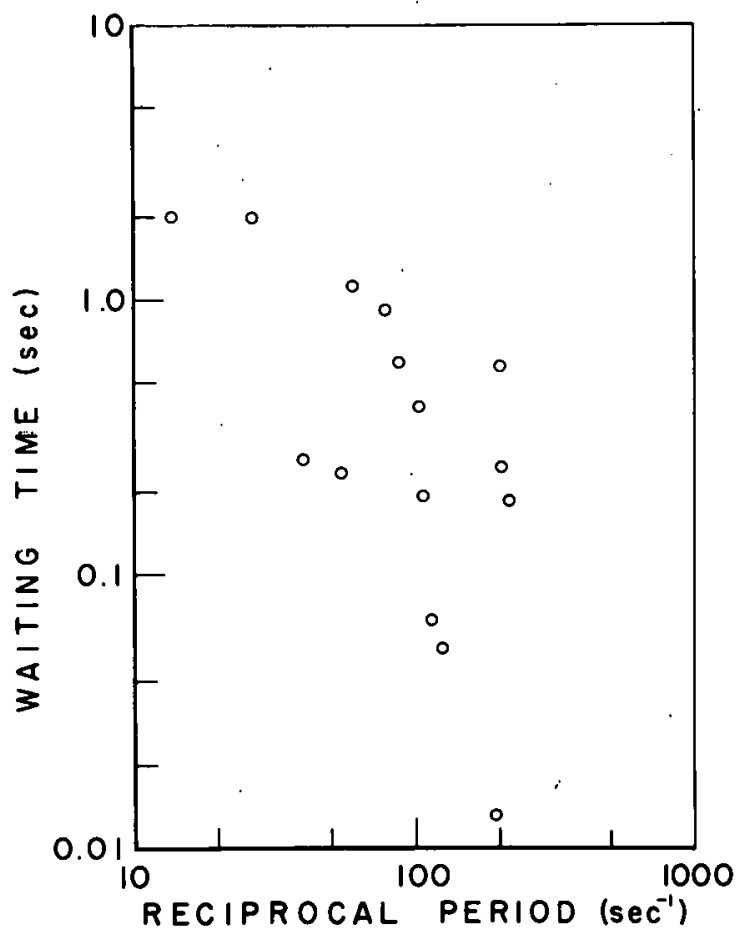

Fig. 25 Estimated waiting time for attainment of stable reactor period vs reciprocal period. 
test with the safety scram circuits in operation. The level safety was set to scram at $100 \mathrm{kw}$, the period circuit was set to scram all periods shorter than $1 \mathrm{sec}$, and the reactivity was inserted at the maximum available rate of $20 \mathrm{\phi} / \mathrm{sec}$. Under normal conditions this ramp would result in a minimum period of $20 \mathrm{msec}$. In the single test performed, the period circuit scrammed the reactor and the power burst was terminated at a relatively low power level, before the reactor period became shorter than $50 \mathrm{msec}$.

5. Conclusions. General conclusions regarding the operation of an experimental facility without a neutron source cannot be made on the basis of these tests. However, the following specific points are noted:

(1) Following preliminary tests of the BSR-II at Spert, operation of the reactor was undertaken without an artificial neutron source in the core. Several months of such operation produced no special problems or incidents.

(2) 'The one start-up accident test that was performed by withdrawing the control rods at the maximum available rate resulted in shutdown by the safety system at a relatively low power level, and before the reactor period became shorter than $50 \mathrm{msec}$.

(3). Significant delays can exist between the injection of reactivity and the allainment of a stable period. While such delays are wellknown for fast systems such as Godiva [11], the present experiments demonstrate that significant delay can also exist for thermal reactors. 


\section{DETERMINATION OF THE REDUCED PROMPT NEUTRON LIFETIME}

\section{A. Introduction}

Prediction of the short-period kinetic behavior of a reactor requires knowledge of the effective properties of the system under transient conditions. These properties may be measured directly by actually performing, as at the Spert facilities, short-period transient experiments. Such dynamic experiments are generally not performed elsewhere, and reliance must be placed on static experimental data for determining dynamic parameters. Hence, it is of interest to determine to what extent dynamic parameters can be measured by means of static techniques.

One such property is the reduced prompt neutron lifetime parameter $\ell / B$ eff, which for the light-water Spert reactors is normally obtained directly from super-prompt-critical, step-transient experiments. Often, at other facilities, $2 / \beta_{\text {eff }}$ is obtained by methods which involve reactor conditions only in the neighborhood of delayed critical; such methods include pile oscillator, pulsed-neutron, reactor-noise, and static $1 / \mathrm{v}$-absorber measurements. For the BSR-II core, $\ell / B$ eff has been determined at ORNL using the pulsed-neutron technique $[12,13]$ and at Spert I from $1 / \nabla$-absorber [14], reactor-noise, and step-transient measurements.

\section{B. Step-Transient Measurements}

The transient value of $\ell / \beta_{\text {eff }}$ for the BSR-II was determined at Spert from a set of approximately 40 step-transient tests, in which the initial reactivity $R$ for each excursion varied from about 1.1 to 1.8 dollars. The reactivity was inserted as a step by rapid ejection of the transient rod, and the amount of reactivity inserted was determined from a prior reactivity calibration of the shim control rods. The rod calibration itself was accomplished by long-period measurements, corresponding to reactivities that were essentially determined by the delayed reactivity term

$$
R_{d}(\alpha)=\sum_{i} \frac{a_{i}}{1+\lambda_{i} / \alpha}
$$

of the in-hour relation

$$
R=\frac{\alpha \ell}{k_{\text {eff }^{\beta} \text { eff }}}+R_{\alpha}
$$

where

$$
\begin{aligned}
& R=\text { total (prompt }+ \text { delayed) reactivity }(\$) \\
& \ell= \text { prompt neutron lifetime }(\mathrm{sec}) \\
& \mathrm{a}_{\mathrm{i}}= \beta_{\mathrm{i}} / \beta=\text { absolute delayed-neutron yield per fission for } \\
& \text { the } i \text { th delayed neutron group }
\end{aligned}
$$




$$
\begin{aligned}
\lambda_{i} & =i^{\text {th }} \text { delayed-neutron-group decay constant } \\
k_{\text {eff }} & =\text { static effective multiplication constant }
\end{aligned}
$$

Setting $k=\left(1-\mathrm{R} \beta_{\text {eff }}\right)^{-1} \approx 1+\mathrm{R} \beta_{\text {eff }}$, where, without introducing appreciable error, the value of Beff in the small correction term $R B_{\text {eff }}$ may be roughly estimated from the buckling, Equation (2) can be rewritten as

$$
\left(R-R_{d}\right)\left(I+R \beta_{\text {eff }}\right)=\frac{l}{\beta_{\text {eff }}} \alpha
$$

Thus, $\ell / \beta_{\text {eff }}$ is obtained as the slope of the linear plot of $\left(R-R_{d}\right)\left(1+R \beta_{\text {eff }}\right)$ as a function of $\alpha$. The experimental plot obtained for the BSR-II reactor is shown in Figure 26. From a least squares linear fit of the data, $\ell / B$ eff $=2.87 \mathrm{x} 10^{-3} \mathrm{sec}$ with a standard deviation from the mean of $1 \%$.

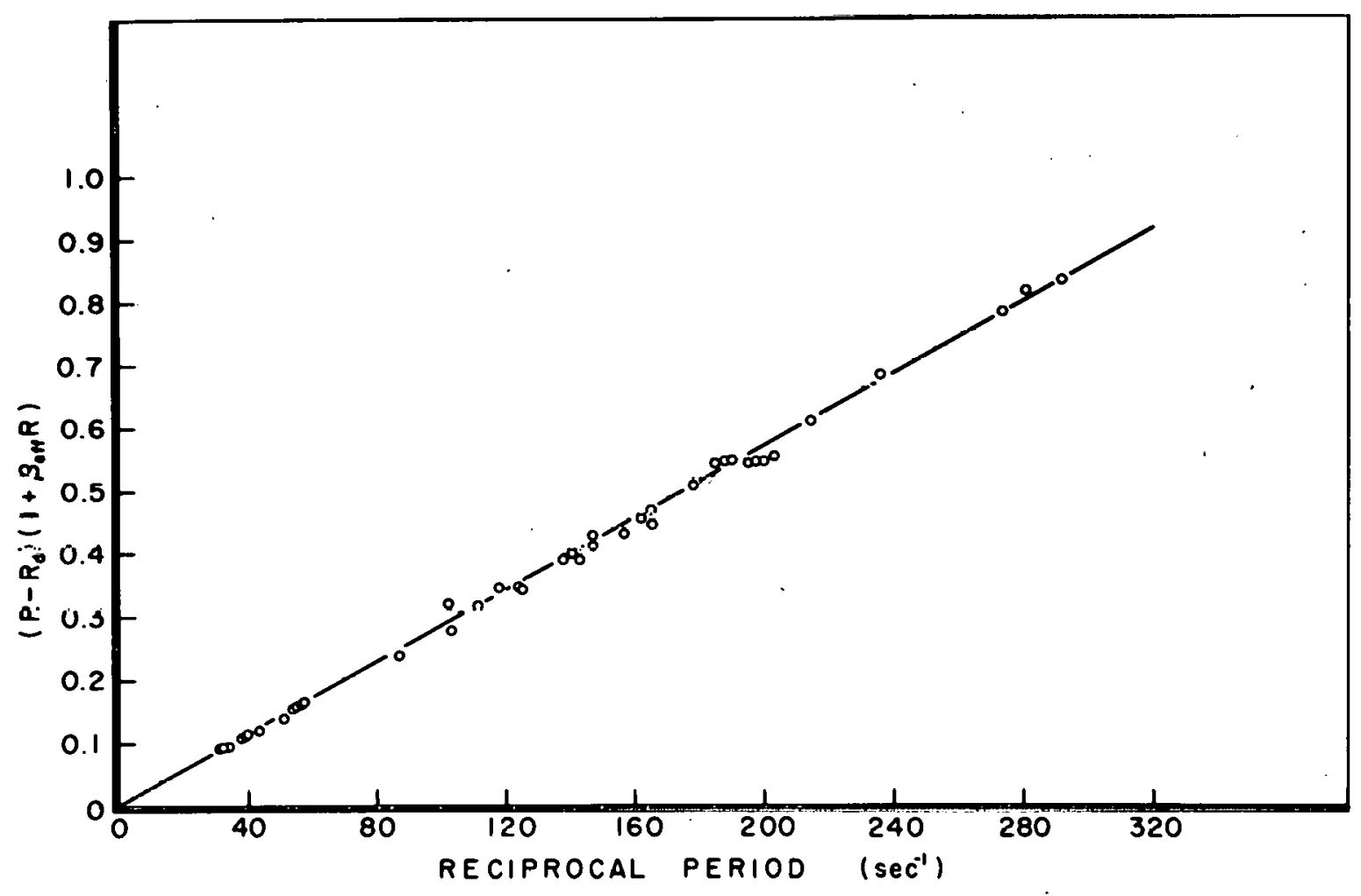

Fig. 26 Prompt reactivity vs reciprocal period for BSR-II.

\section{Reactor-Noise Measurement}

Noise spectrum measurements of the statistical fluctuations in the neutron flux in the BSR-II have been made to obtain, in a manner similar to that of Cohn [15], the shape of the low-power transfer function and the value of $\ell /$ Beff for this reactor. 
Moore [16] has shown that the square modulus of the transfer function is simply related to the mean square amplitude of the noise per unit frequency bandwidth. The noise amplitude measurements in the BSR-II were obtained using a large B-10-lined ionization chamber placed inside the core volume proper to obtain a relatively high overall efficiency. High chamber efficiency is required to obtain a good ratio of coherent reactor noise to random noise. The essential reactor-noise instrumentation used is shown in block diagram form in Figure 27.

In Figure 27, the current signal from the ionization chamber was transmitted to a cathode follower and thence to a dc amplifier, where the signal was amplified approximately $40 \mathrm{db}$ for transmission through the 3000-ft cable to the reactor control center. A band-pass filter, having a frequency range from $2 \times 10^{-1}$ to $2 \times 10^{4} \mathrm{cps}$, enabled measurements to be made of the average noise amplitude over a variable bandwidth. The output from the filter was amplified, using a 100-db step attenuator and dc amplifier combination for precision, and then passed to a calibrated thermocouple detector to provide a dc signal for the strip chart recorder.

The transfer function data in the region of the high frequency roll-off were analyzed using an IBM 650 least squares fitting routine to determine $\ell / B$ eff. The value obtained is given in Table I.

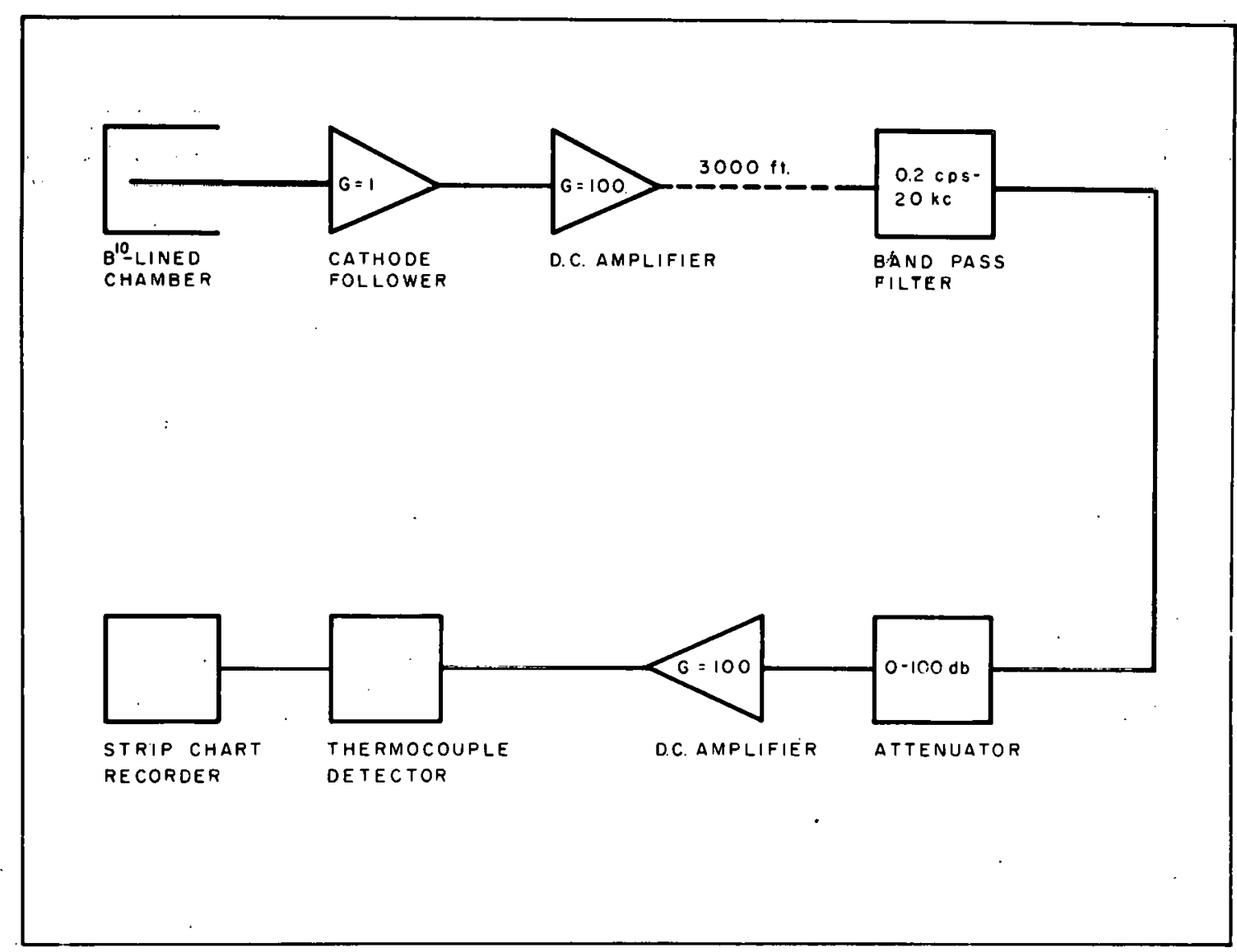

Fig. 27 Block diagram of reactor noise instrumentation. 
D. Static $1 / \mathrm{v}$-Absorber Measurement

In the static technique for the measurement of $\ell / \beta$ eff by use of $1 / v$ absorbers, the perturbation $\delta \Sigma_{a}$ in $a b-$ sorption cross section, introduced by the addition to the reactor of a small quantity of $1 / \mathrm{v}$ absorber such as boron, is related through the lifetime to the resultant reactivity change in dollars $\mathrm{R}$ by

$$
\frac{\ell}{\beta_{\text {eff }}}=\frac{R}{\sigma_{\text {ao }} v_{o} N_{\text {eff }}}
$$

where $\sigma_{a o}$ is the boron absorption cross section at $\mathrm{v}_{0}=2200 \mathrm{~m} / \mathrm{s}$ and $\mathrm{N}_{\text {eff }}$ is a weighted average of the actual boron concentration $N(\overline{\mathbf{r}})$ distributed through the reactor and is defined by

$$
N_{e f f}=\frac{\int N(r) d V \sum_{j} \sigma_{a j^{\phi^{*}}} o j^{\phi} j}{\int d V \sum_{j} \sigma_{a j} \phi^{*} \circ j^{\phi} j}
$$

Here, the volume integration is taken over the entire reactor, and for the $j^{\text {th }}$ neutron energy group, $\phi^{*}$ oj is the unperturbed adjoint flux, $\Phi_{j}$ the perturbed flux and, assuming a $1 / v$ dependence for boron over the entire neutron spectrum, $\sigma_{\text {aj }}$ is given by

$$
\sigma_{a j}=\sigma_{a 0} v_{0} v_{j}^{-1 .}=(755 \text { barns })\left(2200 \mathrm{~m} / \mathrm{s}^{-1} \mathrm{v}_{j}^{-1}\right.
$$

Specialization of Equation (5) to a Spert two-region (core and water... reflector) reactor model yields

$$
\mathbb{N}_{\text {eff }}=f N_{c}+(1-f) N_{r}=[1-(1-w) f] N_{r}
$$

where $\mathrm{N}_{\mathrm{c}}$ and $\mathrm{N}_{\mathrm{r}}$, respectively the uniform boron concentrations in the core and water-reflector regions, are related through the volume fraction of water $\mathrm{w}$ in the core by $\mathrm{N}_{\mathrm{c}}=\mathrm{wN}_{\mathrm{r}}$, and where

$$
f=\frac{\int_{\text {Core }} \sum_{j} \sigma_{a j} \Phi^{*} \circ j^{\Phi} j}{\int_{\text {Reactor }} d V \sum_{j} \sigma_{a j} \Phi^{*} \circ j^{\phi} j}
$$

measures the importance of poisoning of the entire reactor. 
The determination of $\ell / \beta$ eff in Equation (4) thus involves the measurement of the reactivity change $R$ when the entire reactor is poisoned and also the measurement of the weighting factor $f$ (or equivalently, $1-f$ ) through the reactivity change obtained when only the core (or reflector) is separately poisoned.

For the BSR-II, experimental determination of the reflector worth 1-f was accomplished by separately poisoning the reflector water, using a watertight aluminum tank [14]. The experiment yielded a value of 0.81 for the weighting function [1 - (1-w)f] appearing in Equation (6). The static absorber value obtained for $\ell / \beta$ eff is given in Table I, together with the ORNL pulsed-neutron result and the Spert pile-noise and step-transient values. Within experimental error, very good agreement is obtained between the results given by the $1 / \mathrm{v}$-absorber and dynamic methods. 


\section{REFERENCES}

1. E. G. Silver; J. Lewin, Safeguard Report for a Stainless Steel Research Reactor for the BSF (BSR-II), ORNL-2470 (August 11, 1958).

2. Spert Project Quarterly Technical Report, 4th Qtr 1959, IDO-16616, pp 3-13 (1960).

3. Spert Project Quarterly Technical Report, 1st Qtr 1960, IDO-16617, pp 3-6 (1961).

4. Spert Project Quarterly Technical Report, 2nd Qtr 1960, IDO-16640, pp 3-9 (1961).

5. F. L. Bentzen, The Merits of Inherent Shutdown vs Mechanical Shutdown of a Plate-Type, Water-Moderated and -Reflected Reactor In a Runaway Condition, IDO-16722 (November 3, 1961).

6. J. E. Grund, J, Ronsick, Spert Projecl Quarterly Technical Report, 3rd Qtr 1959, IDO-16606, pp 7-12 (1960).

7. R. E. Heffner, Damage to Stainless Steel Fuel in Spert Reactors, DO-16729 (November 22, 1961).

8. T. Quigley et al, Quarterly Progress Report, Reactor Projects Branch, 3rd Qtr 1958, IDO-16512, pp 8-18 (1959).

9. Quarterly Progress Report, Reactor Projects Branch, 4th Qtr 1958, IDO16537 (1959).

10. Quarterly Progress Report, Reactor Projects Branch, 1st Qtr 1959, IDO16539 (1959).

11. G, E. Hansen, "Assembly of Fissinnahle Material in the Presenoe of a Woals Neutron Source”, Nuclear Science and Engr, $\underline{8}$, pp 709-18 (1960).

12. K. M. Henry et al, "Prompt Neutron Generation Time to Effective Delayed Neutron Ratio of the Bulk Shielding Reactor - $\Pi^{\prime}$, Trans. Amer. Nucl. Soc., 2-2, p 28 (November 1959).

13. E. G. Silver et al, "Measurements of the Reactivity Worth of Control Rods by the Pulsed Neutron Technique", Trans. Amer. Nucl. Soc., 3-1, p 278 (June 1960).

14. A. H. Spano, Perturbation Measurement of $\ell / B$ eff using a $1 / \mathrm{v}$-Absorber, IDO-16638 (March 1961).

15. C. E. Cohn, "Determination of Reactor Kinetic Parameters by Pile Noise Analysis", Nuclear Sci. and Eng., 5, pp 331-335 (1959).

16. M. N. Moore, "The Determination of Reactor Transfer Functions from Measurements at Steady Operation", Nuclear Sci. and Eng., 3, pp 387-394 (1958). 


\section{APPENDIX A}

\section{POWER AND TEMPERATURE DATA FROM SELF-LIMITING POWER EXCURSIONS}

Appendix A contains time plots (Figures A-1 through A-8) of the reactor power and the maximum recorded fuel plate surface temperature for selected self-limiting power excursion tests that were performed during the experimental program conducted at Spert with the BSR-II reactor.

The power data were taken from the recording oscillograph traces of an ion chamber whose current-to-power relationship had been determined previously by calormetric methods with an uncertainity of approximately $\pm 5 \%$.

The temperature data were taken using chromel-alumel thermocouples resistance-welded to the fuel plate surfaces. The temperature traces shown in the figures are those for the hottest measured temperature for each test.

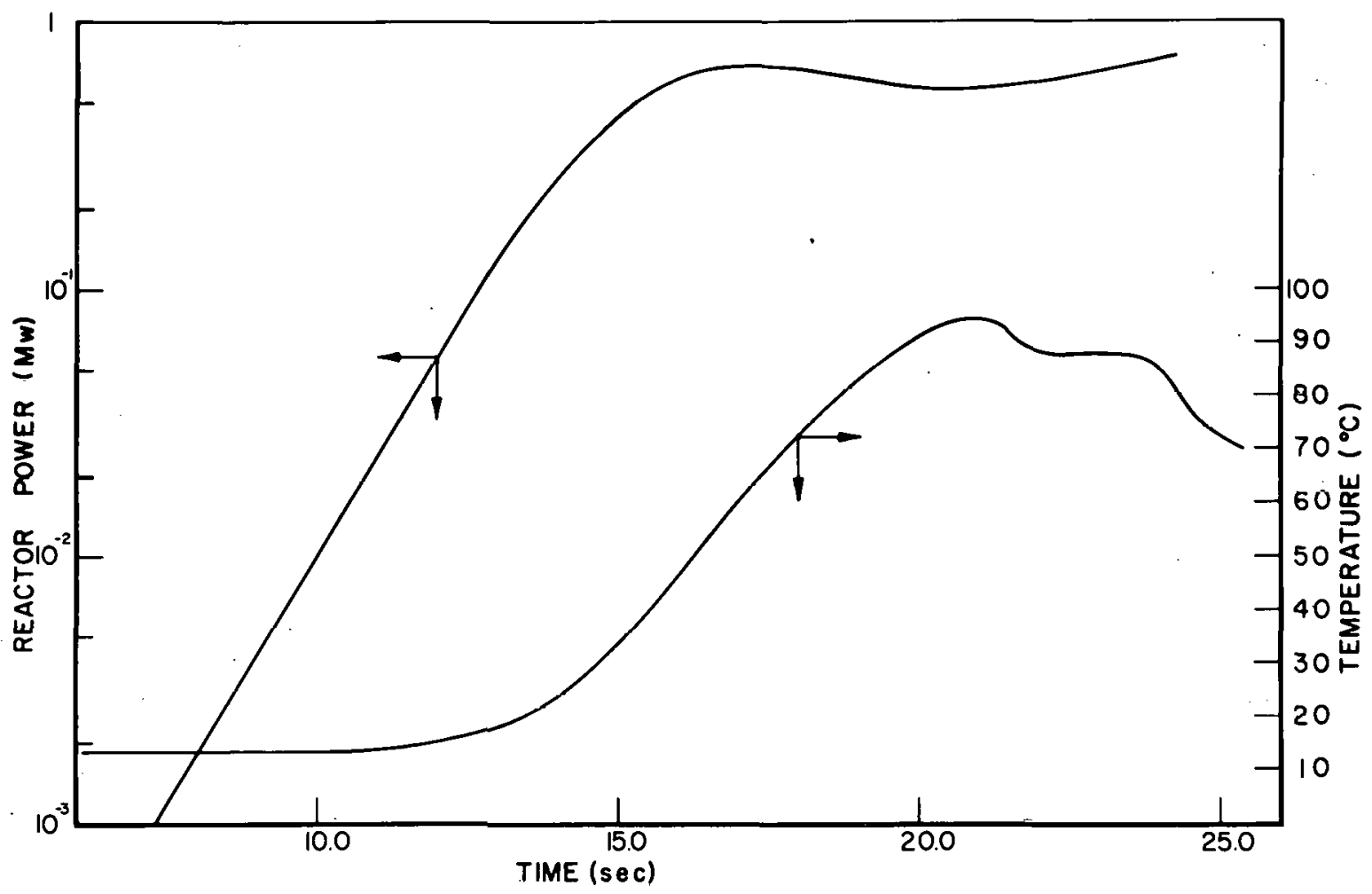

Fig. A-1 Self-11miting test, $\tau_{0}=1.12 \mathrm{sec}$. 


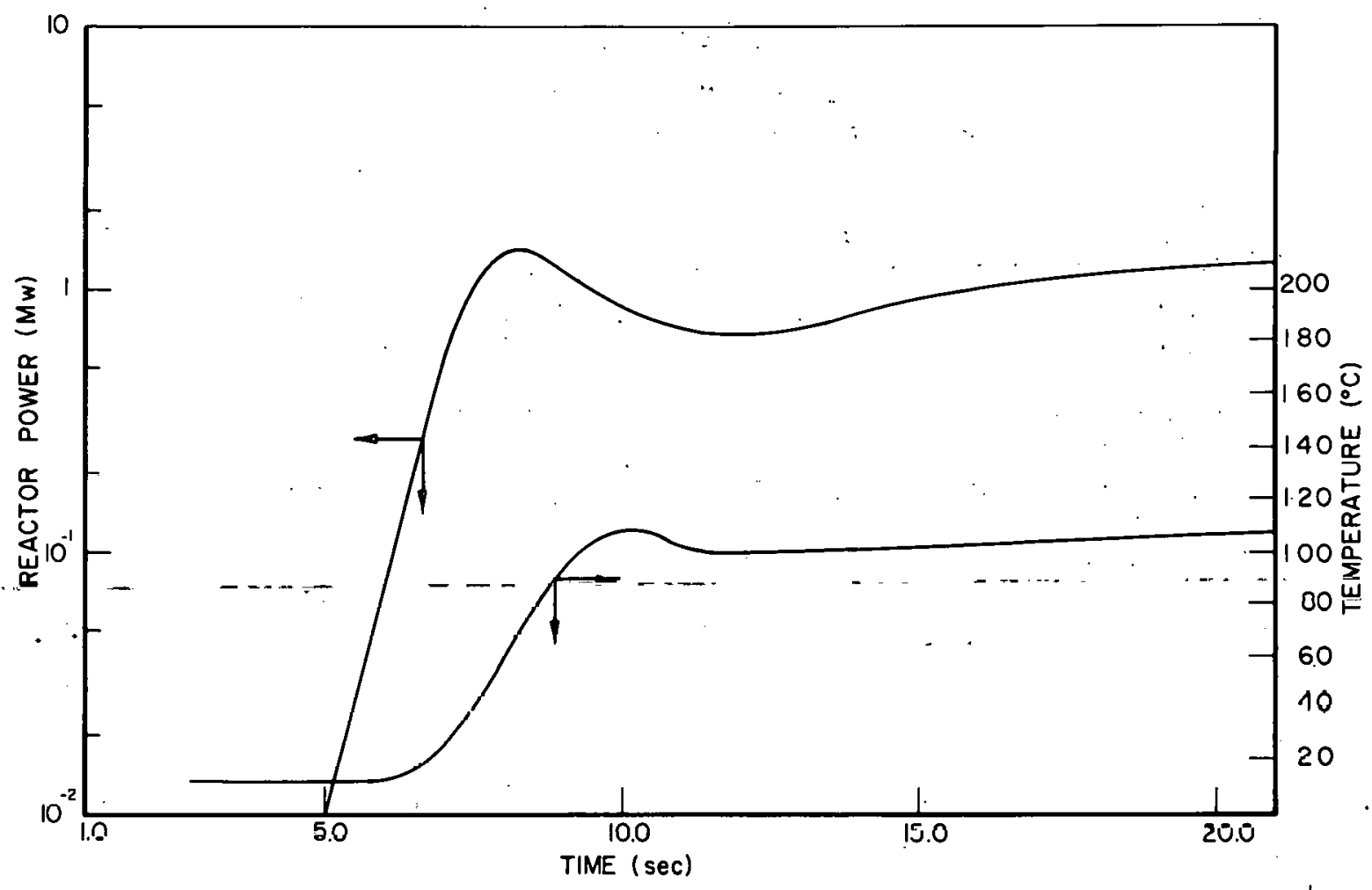

Fig. A-2 Self-limiting test, $\tau_{0}=540 \mathrm{msec}$.

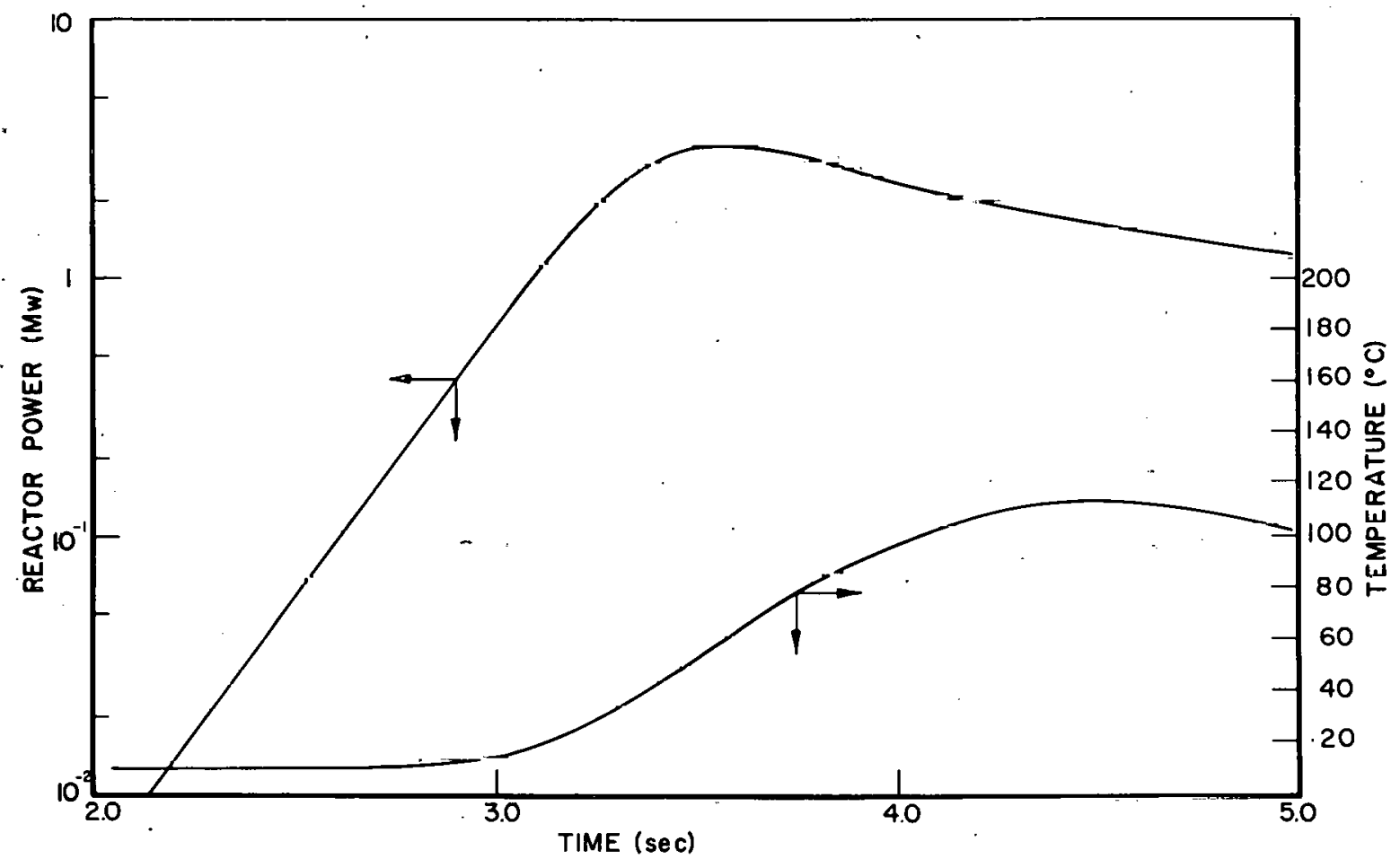

Fig. A-3 Self-liniting tèst, $\tau_{0}=190 \mathrm{msec}$. 


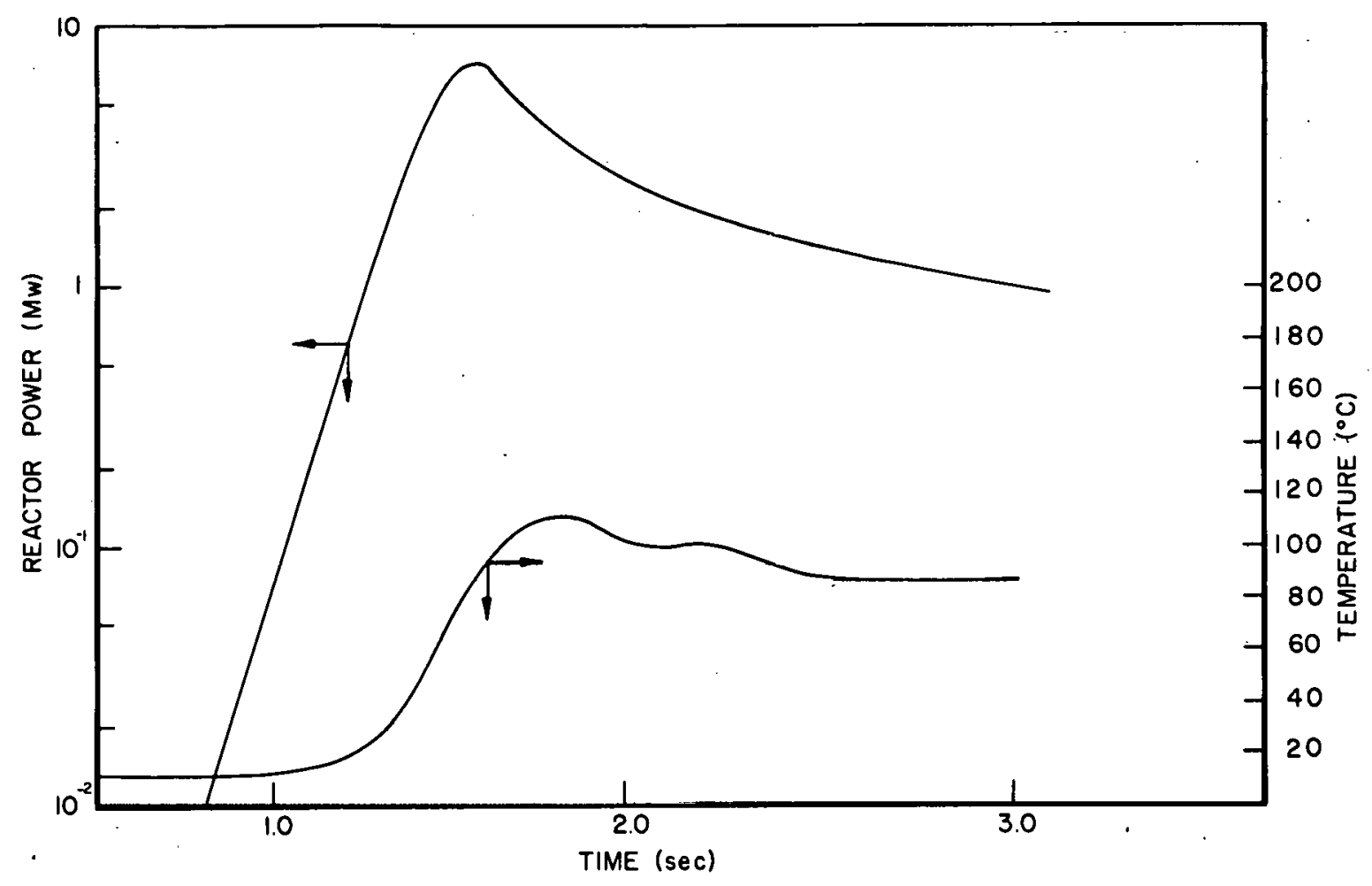

Fig. A-4 Self-limiting test; $\tau_{0}=87 \mathrm{msec}$.

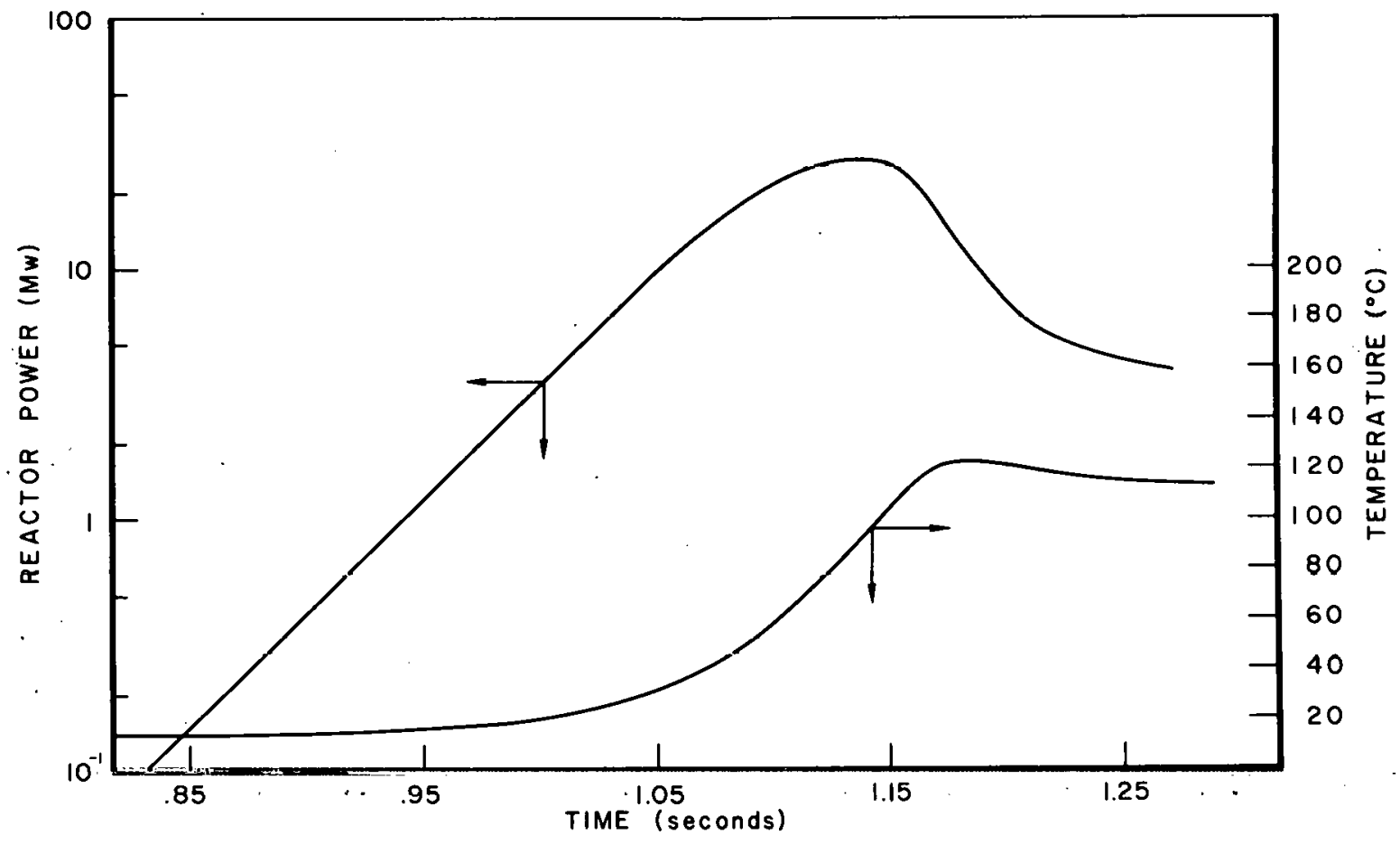

Fig, A-5 Self-limiting test, ${ }^{2} \tau_{0}=55 \mathrm{mse}$. 


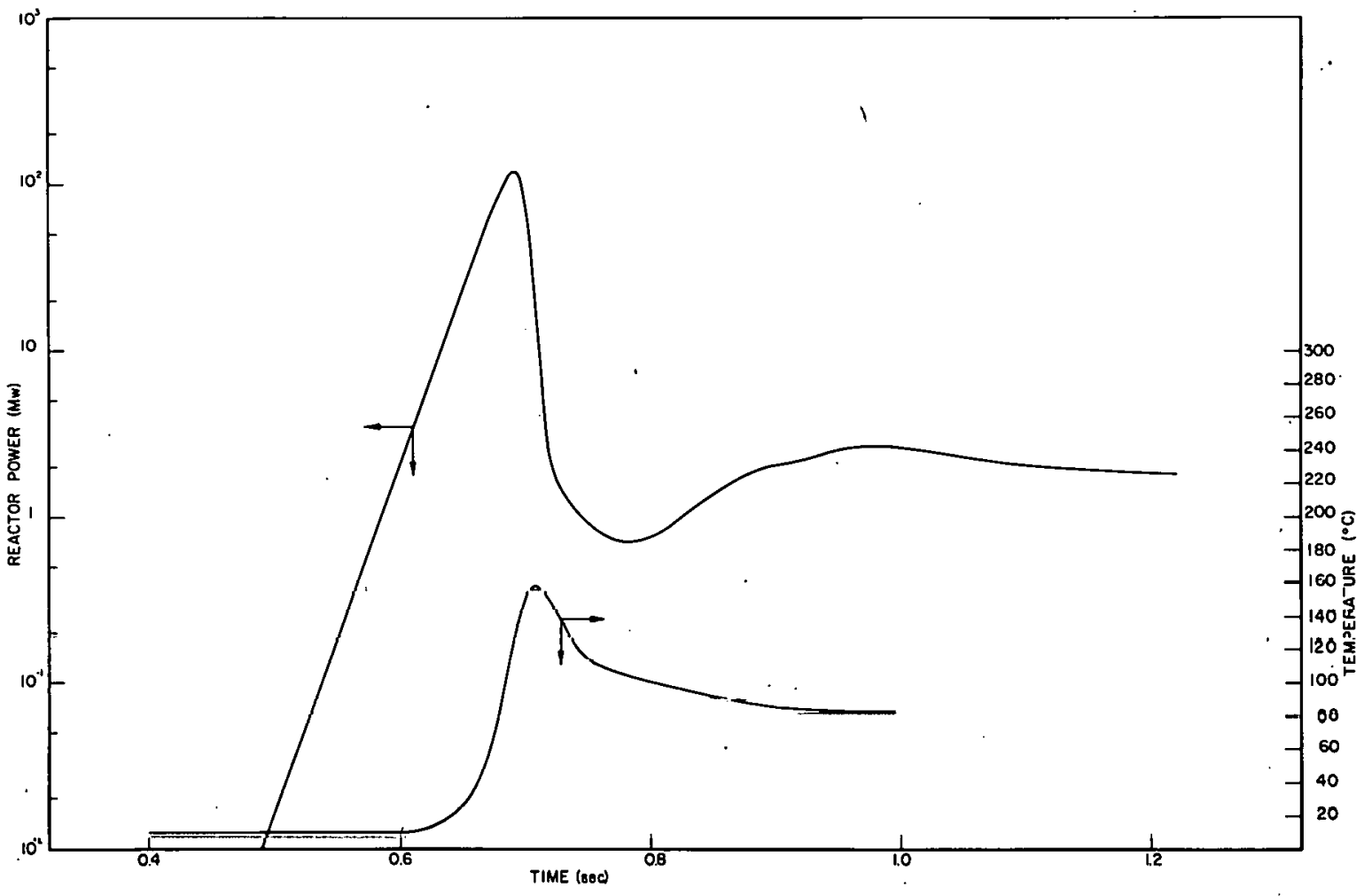

Fig. A-6 Self-limiting test, $\tau_{0}=20.4 \mathrm{msec}$.

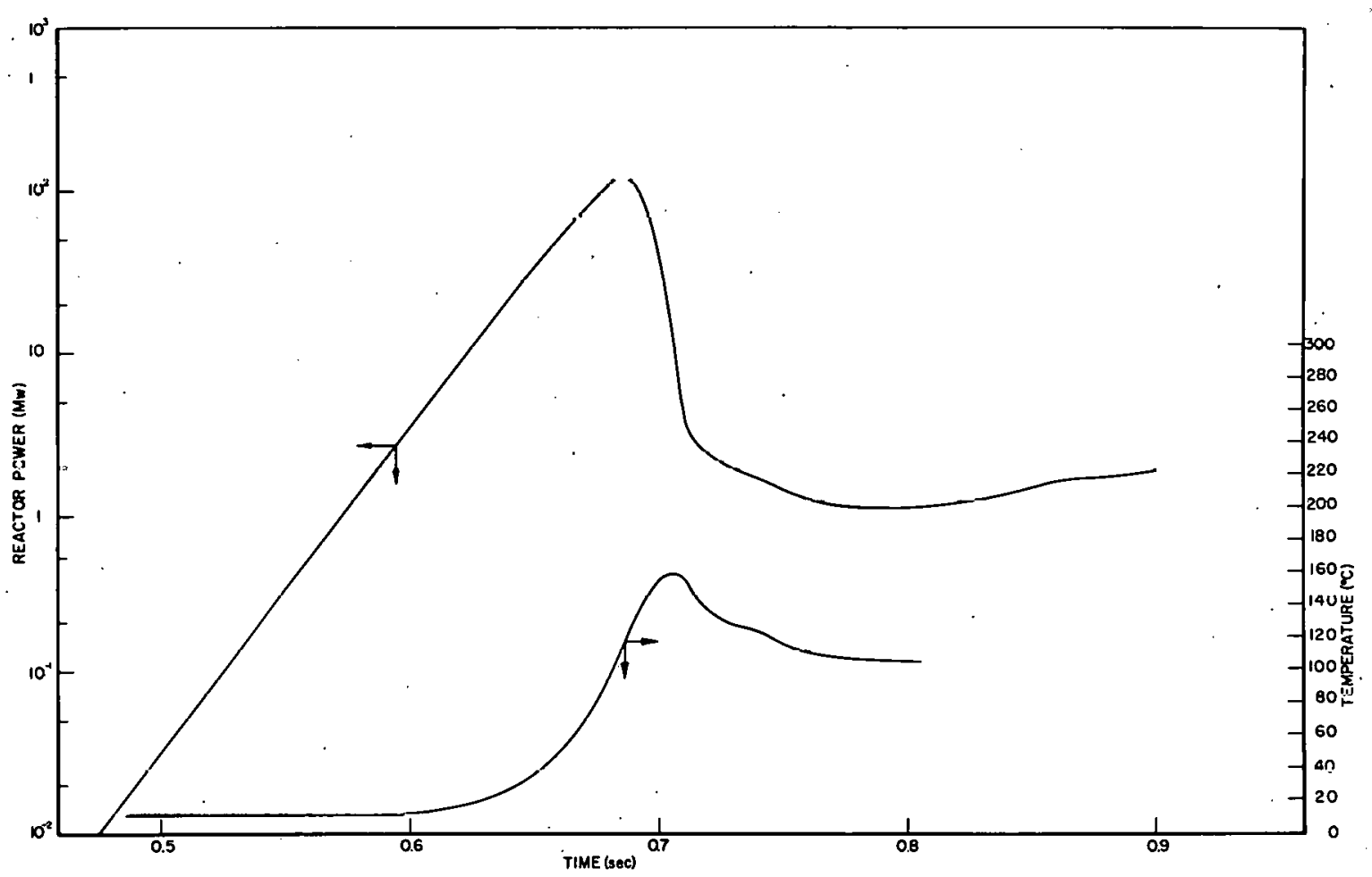

Fig. A-7 Self-limiting test, $\tau_{0}=19.6 \mathrm{msec}$ 


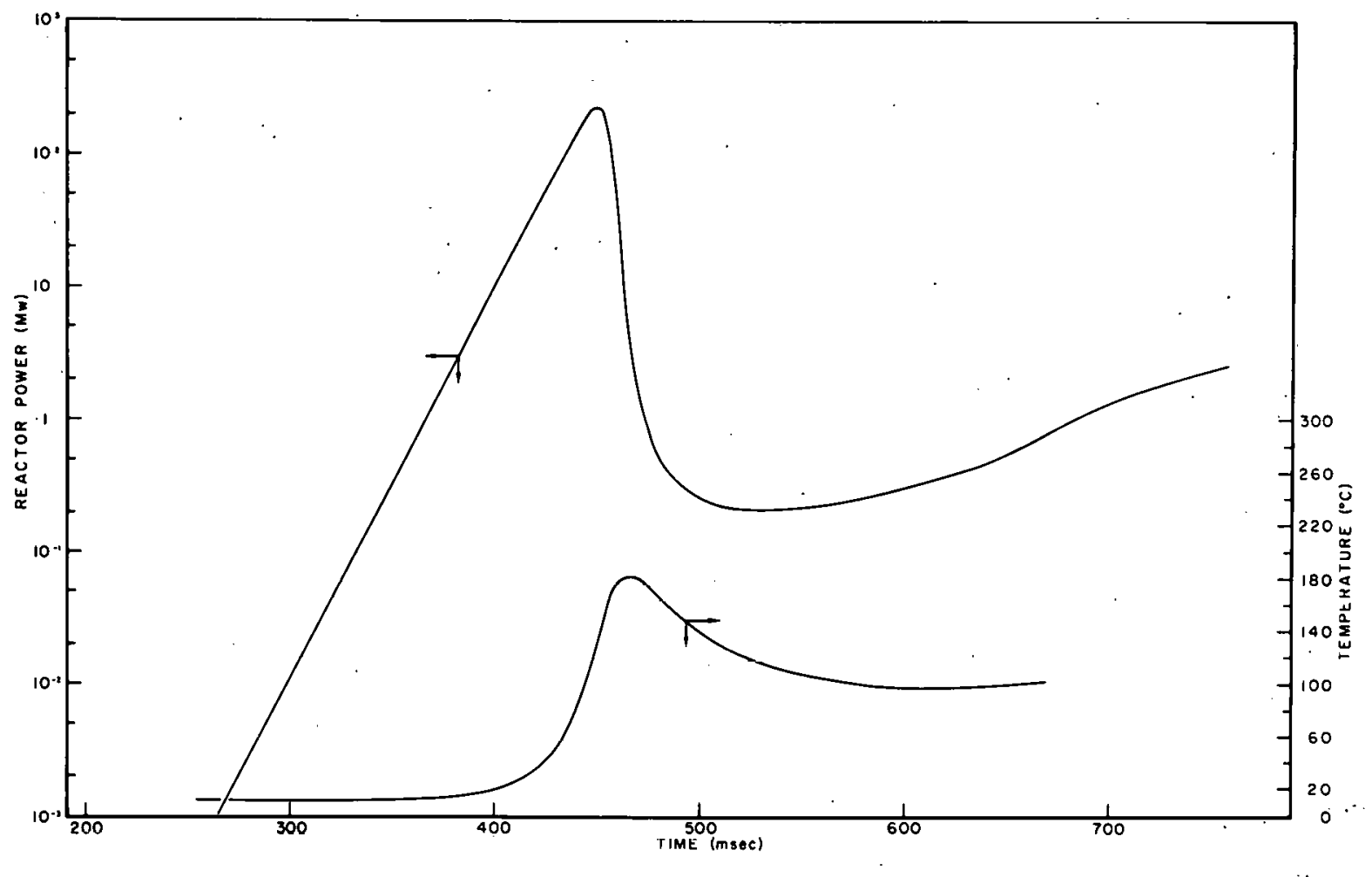

Fig. A-8 Self-limiting test, $\tau_{0}=15 \mathrm{msec}$. 


\section{APPENDIX B}

\section{COMPARISON OF MECHANICAL AND SELF-SHUTDOWN POWER DATA}

Appendix B contains time plots (Figures B-1 through B-8) of the reactor power behavior during selected power excursion tests for which the BSR-II safety system was in operation. These data are compared with the self-limiting power excursion behavior which was either determined experimentally or estimated on the basis of an assumed power burst shape.

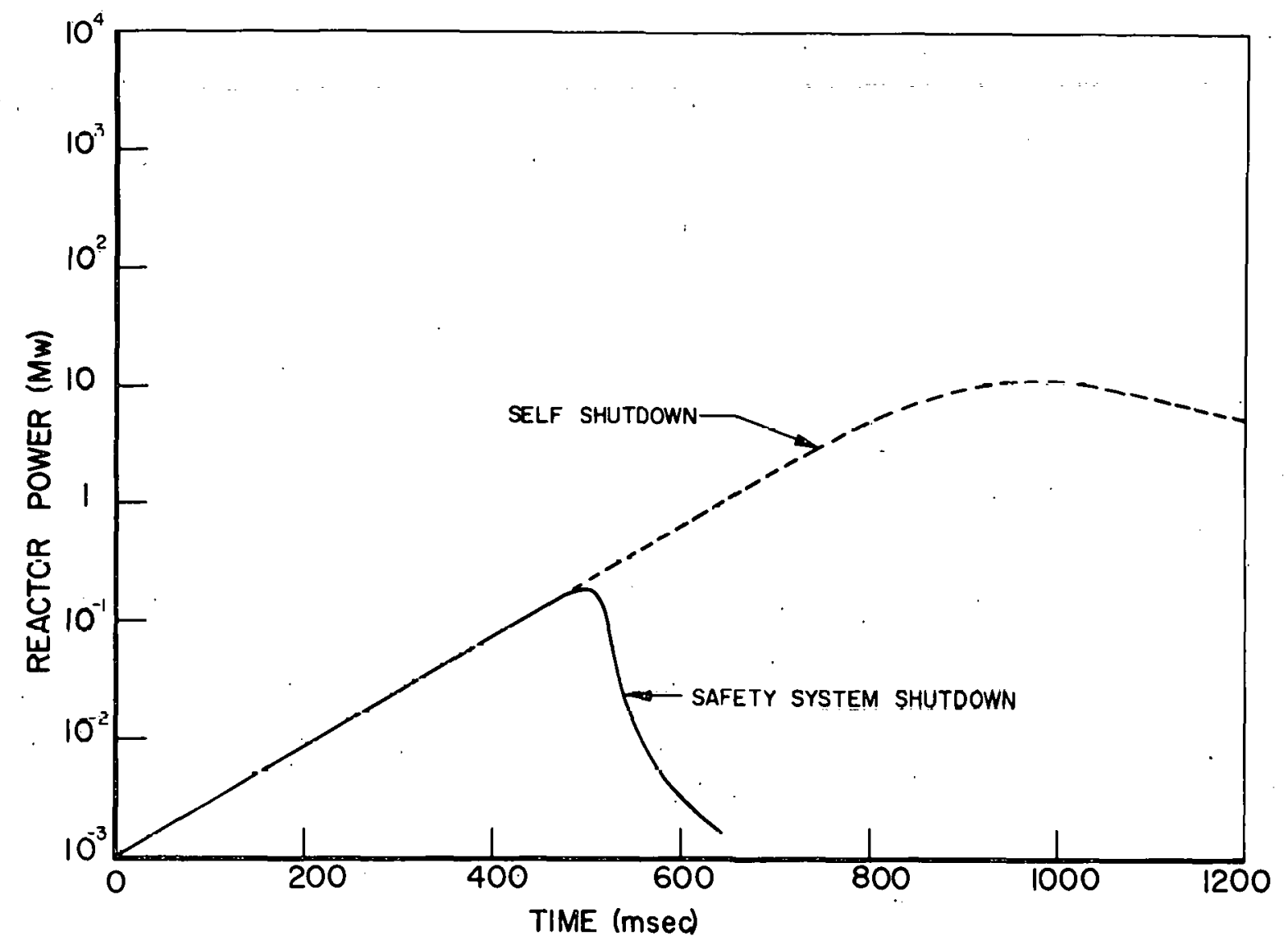

Fig. B-1 Three-rod level scram, $\tau_{0}=75 \mathrm{msec}$. 


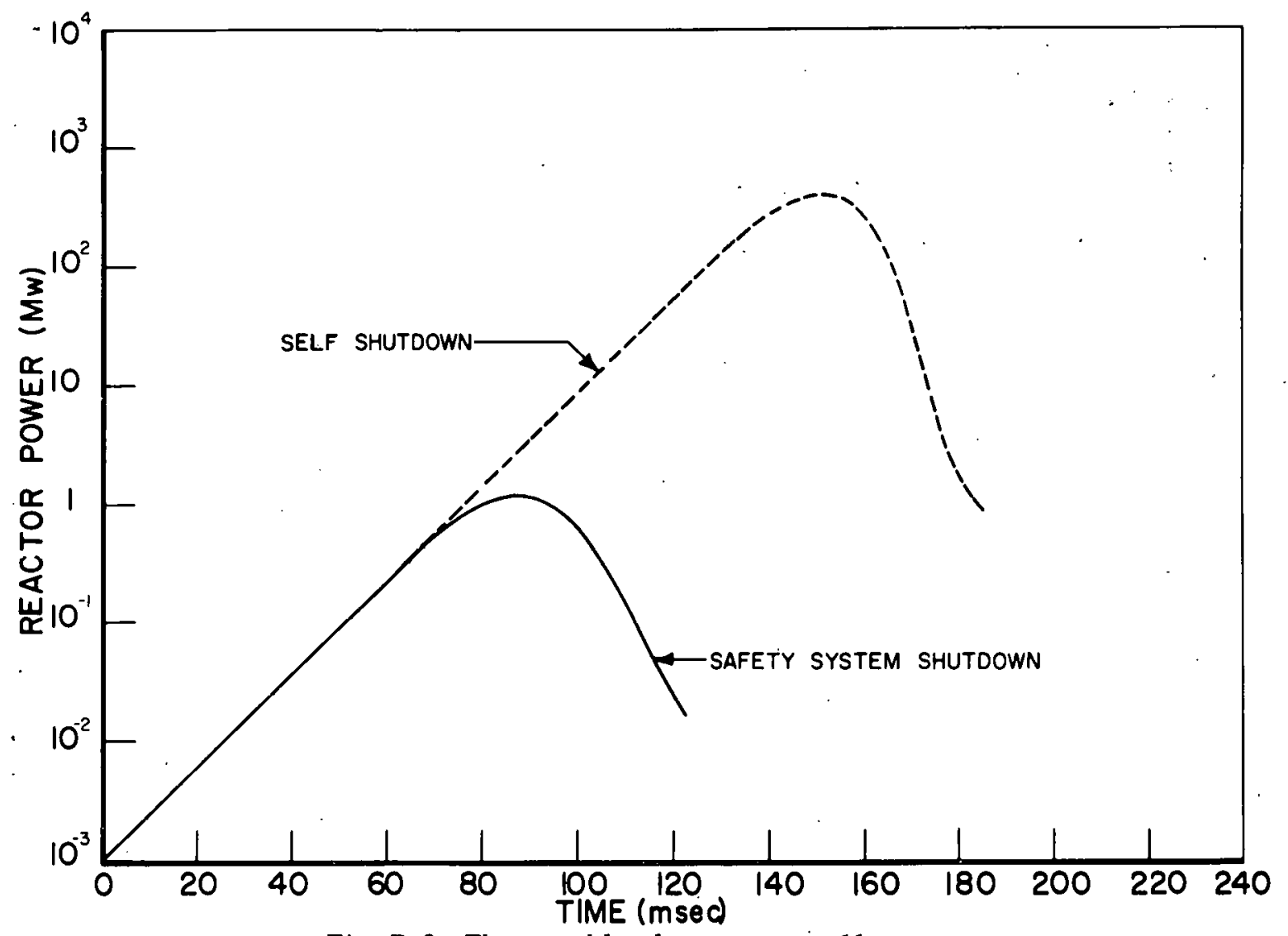

Fig. B-2 Three-rod level scram, $\tau_{0}=11 \mathrm{msec}$.

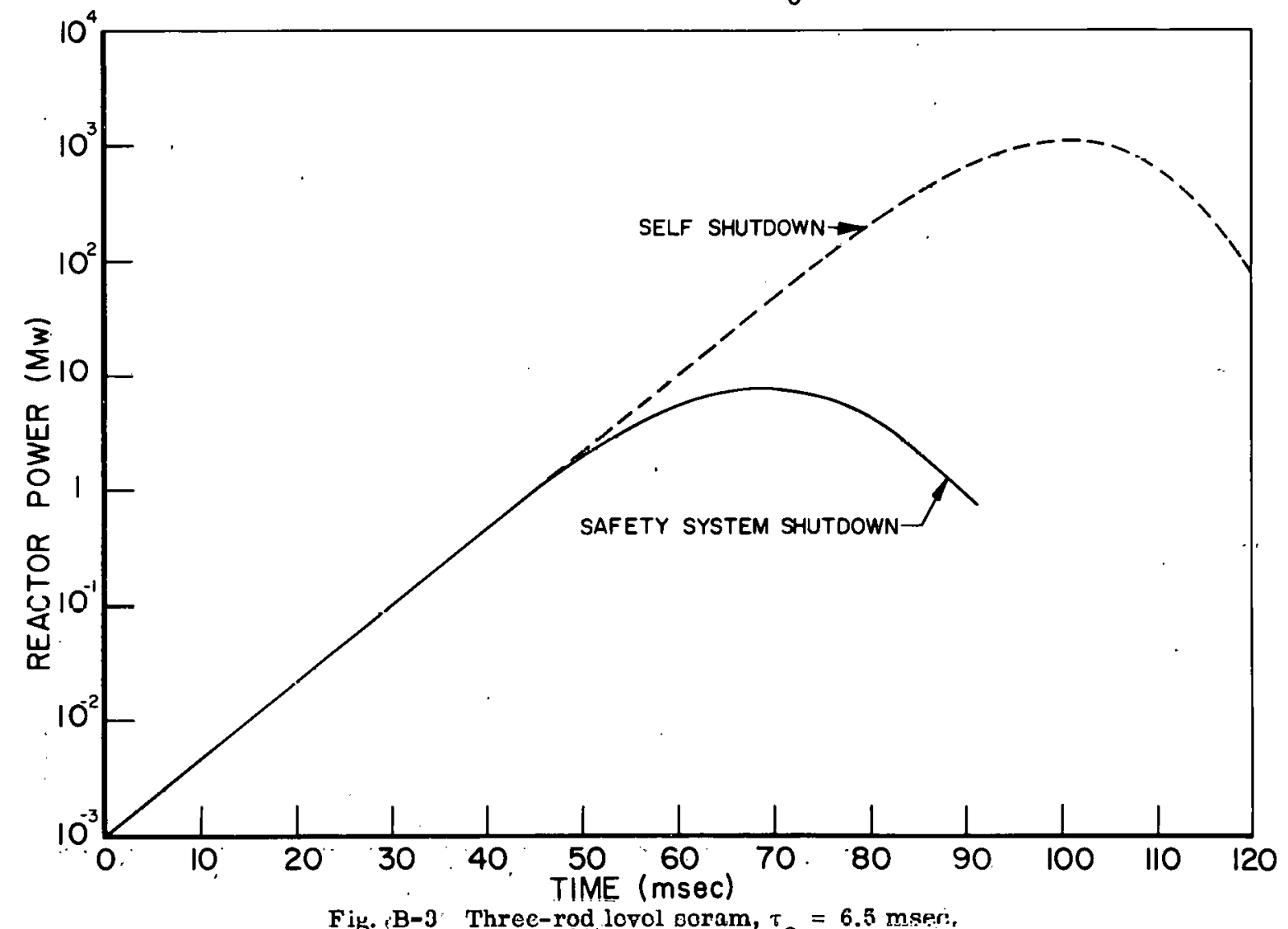

Fig. B-3 Three-rọ lovol soram, $\tau_{0}=6.5$ mseri, 

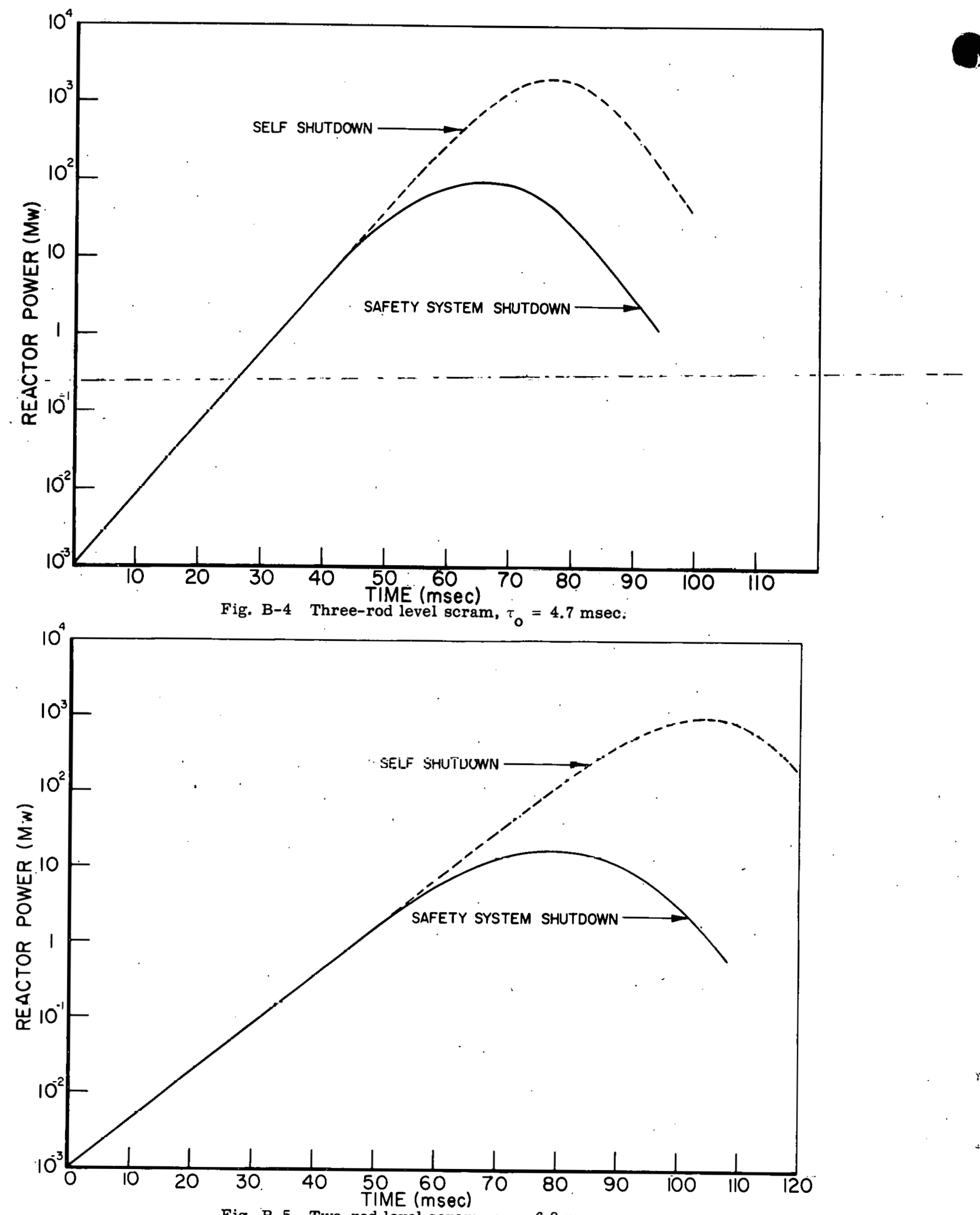

Fig. B-5 Two-rod level scram, $\tau_{0}=6.8 \mathrm{msec}$. 


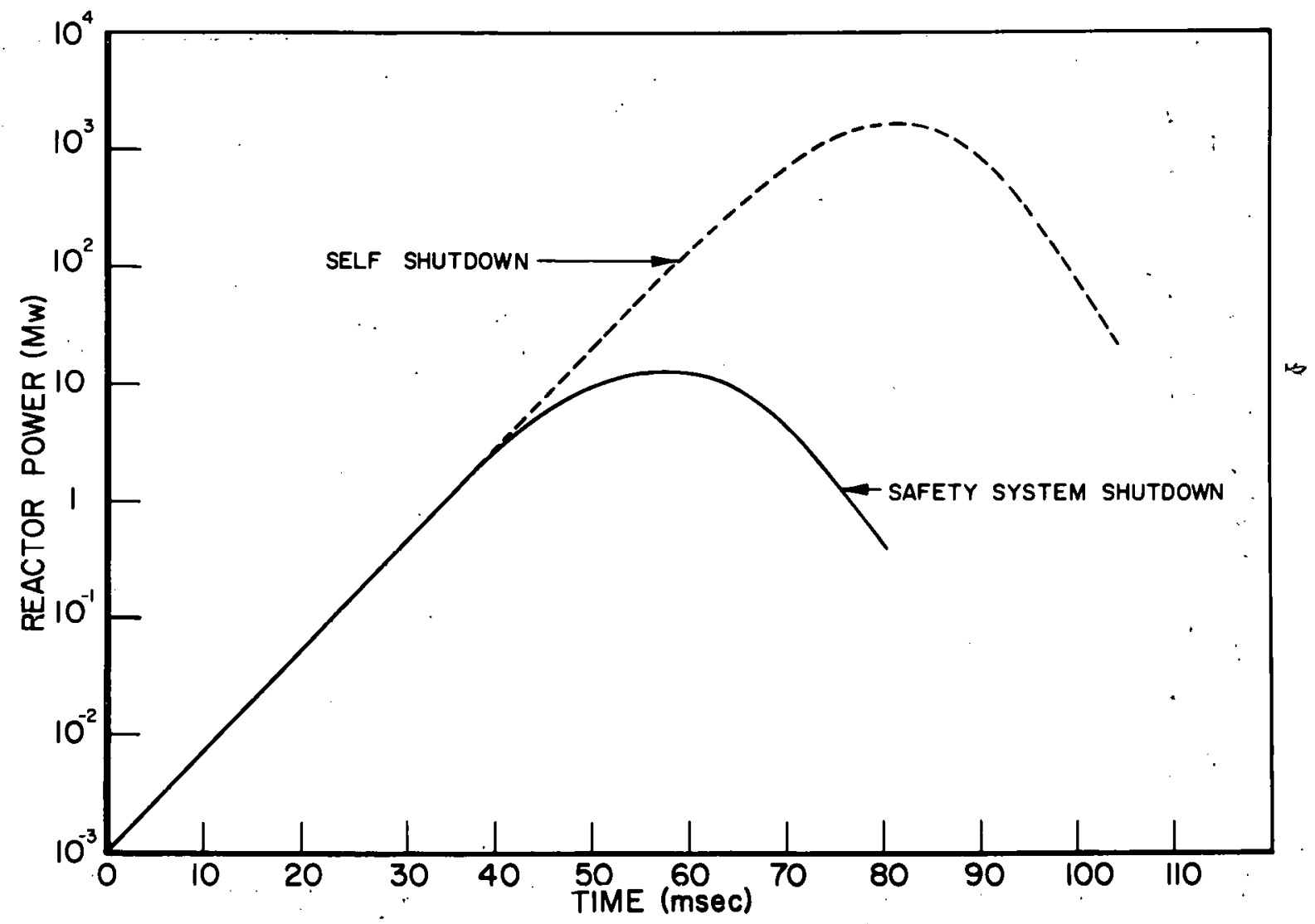

Fig. B-6 Four-rod level scram, $\tau_{0}=5.0 \mathrm{msec}$.

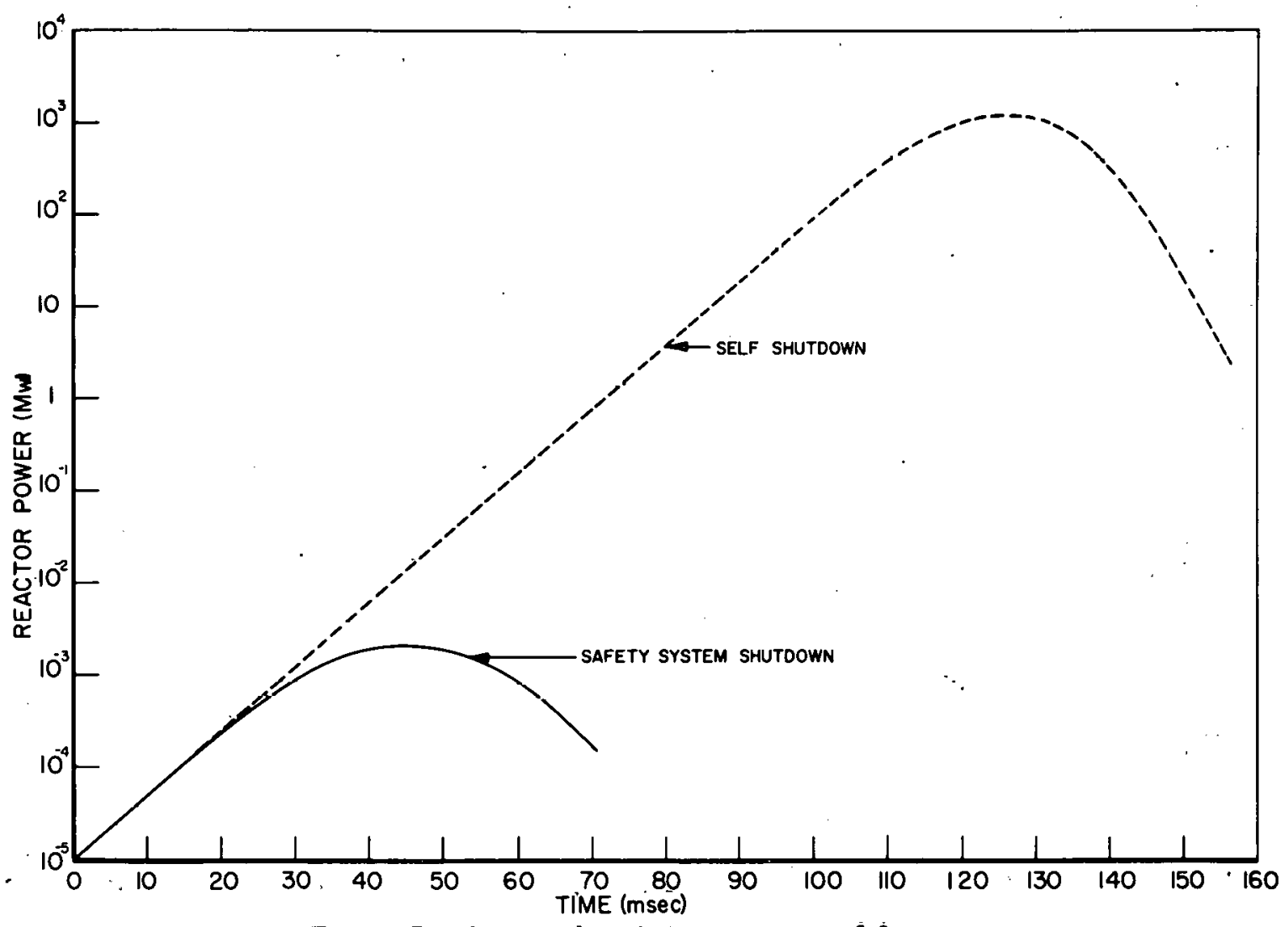

Fig. B-7 Three-rod period scram, $\tau_{0}=6.2 \mathrm{msec}$. 


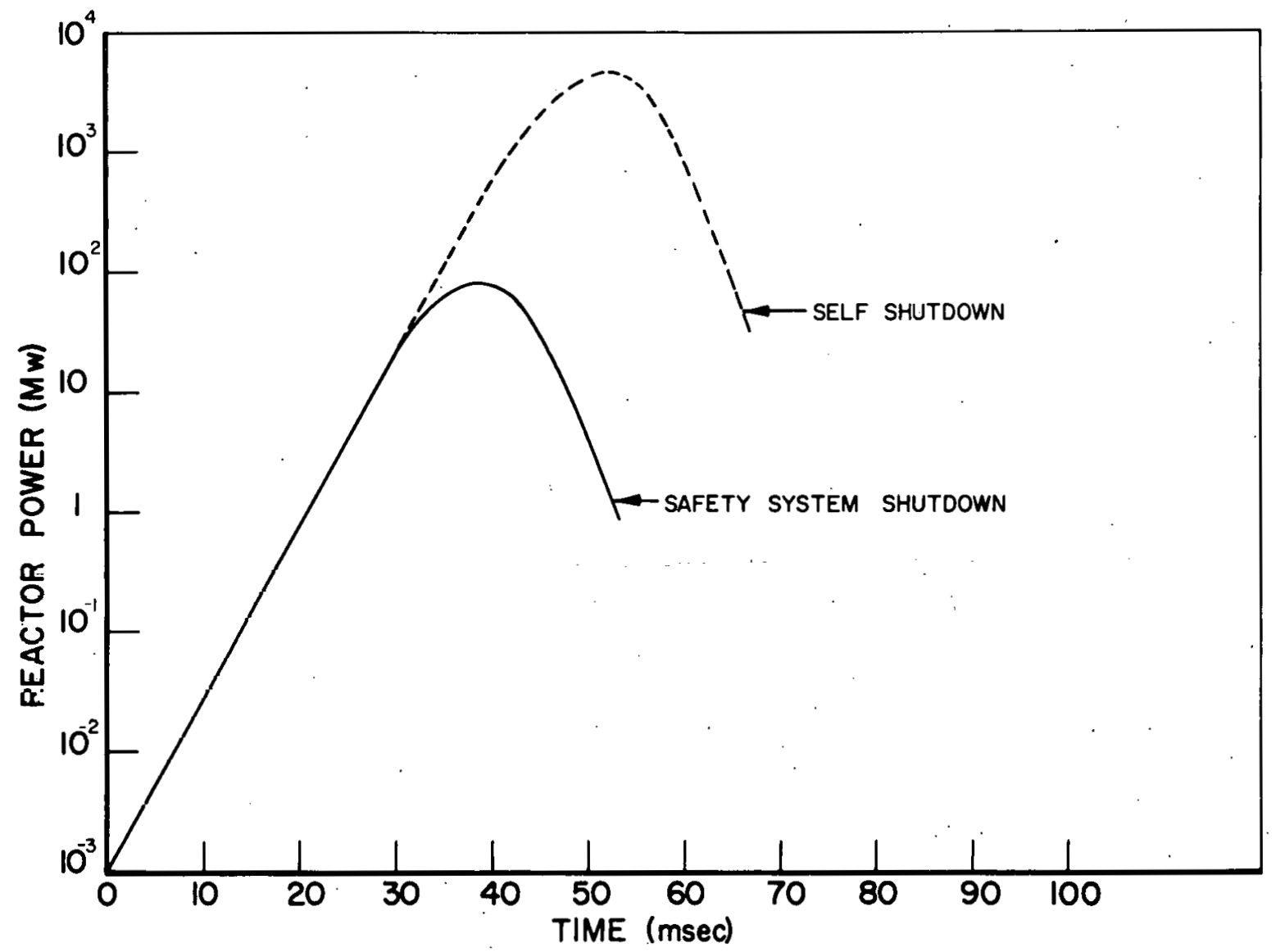

Fig: B-8 Three-rod period scram, $\tau_{0}=3.0 \mathrm{msec}$.

38 